$\therefore$

NASA TECHNICAL

MEMORANDUM

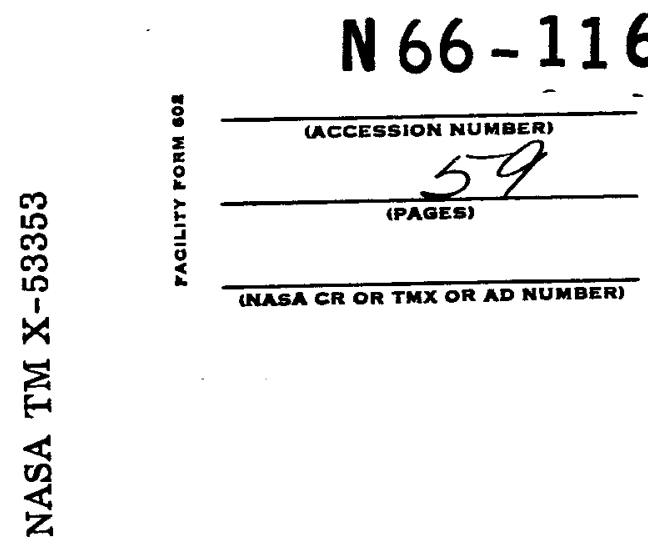

NASA TM X-53353

September 17, 1965

\title{
PRESSURE DISTRIBUTION AND BUBBLE FORMATION INDUCED BY LONG ITUD INAL VIBRATION OF A FLEXIBLE LIQUID-FILLED CYLINDER
}

by R. J. SCHOENHALS AND T. J. OVERCAMP

Propulsion and Vehicle Engineering Laboratory

NASA

George C. Marshall

Space Flight Center,

Huntsville, Alabama

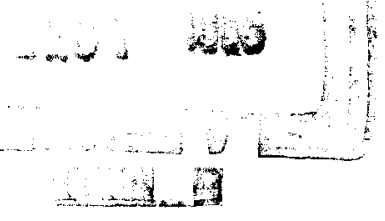




\author{
TECHNICAL MEMORANDUM X-53353 \\ PRESSURE DISTRIBUTION AND BUBBLE FORMATION \\ INDUCED BY LONGITUDINAL VIBRATION OF \\ A FLEXIBLE LIQUID-FILLED CYLINDER
}

By

R. J. Schoenhals and

T. J. Overcamp

George C. Marshall Space Flight Center

Huntsville, Alabama

\begin{abstract}
$1 / 626$

Longitudinal vibration of a flexible liquid-filled cylinder was studied analytically and experimentally. Experimental observations correlated satisfactorily with analysis of the system. Results are presented in terms of predicted and measured pressure amplitudes as well as the acceleration levels required to produce bubble formations. Knowledge of the pressure distribution enables one to estimate the vibration limits for which the fluid remains entirely in the liquid state.
\end{abstract}

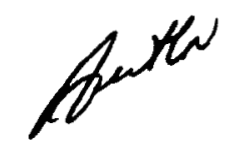

NASA - GEORGE C. MARSHALL SPACE FLIGHT CENTER 
NASA - GEORGE C. MARSHALL SPACE FLIGHT CENTER

TECHNICAL MEMORANDUM X-53353

PRESSURE DISTRIBUTION AND BUBBLE FORMATION

INDUCED BY LONGITUDINAL VIBRATION OF

A FLEXIBLE LIQUID-FILLED CY LINDER

By

-R. J. Schoenhals

and

T. J. Overcamp

PROPULSION CRYOGENICS SECTION

APPLIED MECHANICAL RESEARCH BRANCH

PROPULSION DIVISION

PROPULSION AND VEHICLE ENGINEERING LABORATORY 
TABLE OF CONTENTS

$$
\text { Page }
$$

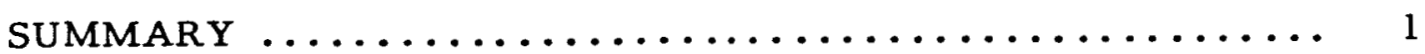

INTRODUCTION $\ldots \ldots \ldots \ldots \ldots \ldots \ldots \ldots \ldots \ldots \ldots \ldots \ldots \ldots \ldots$

SURVEY OF LITERATURE $\ldots \ldots \ldots \ldots \ldots \ldots \ldots \ldots \ldots \ldots \ldots \ldots \ldots$

SIMPLIFIED ANALYTICAL MODEL $\ldots \ldots \ldots \ldots \ldots \ldots \ldots$

EXPERIMENTAL DETERMINATION OF OSCILLATING

PRESSURES ......................... 8

OBSERVED BUBBLE FORMATIONS $\ldots \ldots \ldots \ldots \ldots \ldots \ldots \ldots$

CONCLUSIONS AND RECOMMENDATIONS $\ldots \ldots \ldots \ldots \ldots \ldots 15$

APPENDIX A - DERIVATION OF EQUATION OF MOTION $\ldots \quad 16$

APPENDIX B - FURTHER DETAILS OF SYSTEM BEHAVIOR. 19

REFERENCES $\ldots \ldots \ldots \ldots \ldots \ldots \ldots \ldots \ldots \ldots \ldots \ldots \ldots \ldots \ldots \ldots \ldots$ 


\section{LIST OF ILLUSTRATIONS}

Figure

Title

Page

1

Longitudinal Vibration of a Flexible Liquidfilled cylinder ..................

Bubble Formations in a Vibrating Liquid........

Experimental Apparatus for Measurement of Oscillating Pressures ..............

$4 a$

Oscillating Pressures with $\Omega=\frac{\pi}{4} \ldots \ldots \ldots \ldots$

Oscillating Pressures with $\Omega=\frac{\pi}{2} \ldots \ldots \ldots \ldots$

$4 c$

Oscillating Pressures with $\Omega=\frac{3}{4} \pi \ldots \ldots \ldots \ldots$

$4 d$

Oscillating Pressures with $\Omega=\pi \ldots \ldots \ldots$

31

$4 e$

Oscillating Pressures with $\Omega=\frac{5}{4} \pi \ldots \ldots \ldots \ldots$

$4 f$

Oscillating Pressures with $\Omega=\frac{3}{2} \pi \ldots \ldots \ldots$

Oscilloscope Display of Oscillating Pressures....

6a Initial Bubble Formations in a Vibrated

$$
\text { Methanol Column }\left(\Omega=\frac{\pi}{4}\right) \ldots \ldots \ldots \ldots \ldots
$$

6b Growth of Bubble Formations in a Vibrated Methanol Column $\left(\Omega=\frac{\pi}{4}\right) \ldots \ldots \ldots \ldots \ldots$

6c Initial Bubble Formations in a Vibrated Methanol Column $\left(\Omega=\frac{\pi}{2}\right) \ldots \ldots \ldots \ldots \ldots \ldots$

$6 d$

Initial Bubble Formations in a Vibrated

Methanol Column $(\Omega=\pi) \ldots \ldots \ldots \ldots \ldots \ldots$ 


\section{LIST OF ILLUSTRATIONS (Cont'd)}

Figure

Title

Page

$6 e$

Initial Bubble Formations in a Vibrated Methanol Column $\left(\Omega=\frac{3}{2} \pi\right) \ldots \ldots \ldots \ldots \ldots$

Initial Bubble Formations in a Vibrated Methanol Column $\left(\Omega=\frac{3}{2} \pi\right) \ldots \ldots \ldots \ldots \ldots$

7

Experimentally Observed Low Frequency

Threshold Acceleration and Comparison

with Analytical Prediction Based on $\mathrm{P}_{\mathrm{T}}=\mathrm{P}_{\mathrm{S}} \cdot 41$

8

Effect of Frequency on Threshold Acceleration

Level for Initiation of Bubble Formation .....

Cylindrical Element of the System..........

Forces Acting on a Fluid Element

Effect of Frequency on Pressure Amplitude At $x / L=0.5$

Effect of Frequency on Threshold Acceleration 


\section{DEFINITION OF SYMBOLS}

Symbol

$a$

A

B

$\mathrm{C}_{1}, \mathrm{C}_{2}$

C

$C^{*}$

D

E

$E_{\mathbf{X}}$

$E^{*}$

$\mathrm{E}_{\mathrm{x}}^{*}$

$E^{\prime}$

En

f

$F_{\mathrm{x}}$

g

$\mathrm{g}_{\mathrm{L}}$

G

\section{Definition}

Fluid acoustic velocity

Fluid cross - sectional area

Fluid bulk modulus

Integration constants

Longitudinal wave velocity, $\sqrt{\frac{E_{x}}{\rho}}$

Complex wave velocity, $\sqrt{\frac{E_{x}^{*}}{\rho}}$

Cylinder diameter

Young's modulus for the container

Effective longitudinal modulus of elasticity

Complex modulus of elasticity, $E^{\prime}+i E^{\prime \prime}$

Complex longitudinal modulus of elasticity

Real component of $E^{*}$

Imaginary component of $\mathrm{E}^{*}$

Vibration frequency, $\frac{\omega}{2 \pi}$

Net longitudinal force acting on a fluid element

Acceleration of gravity

Acceleration amplitude of cylinder, $y_{L} \omega^{2}$

Dimensionless acceleration amplitude, $\frac{g_{L}}{g}$ 


\section{DEFINITION OF SYMBOLS (CONT.)}

Symbol

$G_{T}$

$\mathbf{L}$

$\ell$

$M^{*}$

$N^{*}$

$\mathrm{P}$

$\mathrm{P}_{\mathrm{m}}$

$P_{\text {s }}$

$\mathrm{P}_{\mathrm{T}}$

$P_{u}$

$\Delta \mathrm{P}$

$\Delta \mathrm{P}^{*}$

$\mathbf{r}$

s

$\mathbf{t}$

$\mathbf{u}$

$\mathrm{U}$

$\mathrm{U}_{\mathrm{m}}$
Definition

Threshold acceleration level required to produce bubbles

Length of the liquid column

Length of a thin cylindrical fluid element

Complex amplitude of fluid core motion

Complex amplitude of boundary layer velocity

Pressure

Minimum pressure occurring in the fluid

Fluid saturation pressure

Threshold pressure required to produce bubbles

Ullage pressure

Oscillating pressure amplitude

Complex pressure amplitude

Ratio, $\frac{\mathrm{E}_{\mathbf{X}}}{\mathrm{B}}$

Thickness of container wall

Time

Longitudinal fluid velocity in boundary layer

Fluid core velocity

Maximum core velocity amplitude 


\section{DEFINITION OF SYMBOLS (CONT.)}

Symbol

V

$\mathbf{x}$

$\left(\frac{\mathrm{x}}{\mathrm{L}}\right)_{\mathrm{m}}$

y

$\mathrm{Y}$

$Y_{0}$

$Y_{1}$

$\mathrm{Y}_{\mathrm{L}}$

z

$\alpha$

$\delta_{0}$

$\varepsilon$

$\varepsilon_{\mathbf{X}}$

$\lambda$

$\mu$

$v$

$\rho$

T
Definition

Volume of a cylindrical fluid element

Depth below surface of fluid

Location of maximum pressure amplitude

Radial distance measured normál to cylinder wall

Longitudinal displacement of fluid cross-section

Steady component of $\mathrm{Y}$

Oscillating component of $\mathrm{Y}$

Amplitude of $Y_{1}$ at cylinder base

Distance along cylinder wall (see FIG l0)

Angular deflection of cylinder wall (see FIG 10)

Oscillating boundary layer thickness, $\sqrt{\frac{\omega}{v}}$

Circumferential strain of container wall

Fluid longitudinal strain

W.ave length, $\frac{C}{f}$

Fluid viscosity

Fluid kinematic viscosity, $\frac{\mu}{\rho}$

Fluid density

Wall shear stress 


\section{DEFINTION OF SYMBOLS (CONT.)}

Symbol

$T^{*}$

$\boldsymbol{\sigma}$

$\phi$

$\omega$

$\Omega$

$\Omega^{*}$

()$^{*}$
Definition

Complex amplitude of wall shear stress

Circumferential stress in cylinder wall

Loss factor, $\frac{E^{\prime \prime}}{E^{\prime}}$

Angular frequency of vibration

Dimensionless angular frequency, $\frac{\omega L}{C}$

Complex dimensionless angular frequency, $\frac{\omega L}{C^{*}}$

Complex quantity (time independent) 
TECHNICAL MEḾORANDUM X-53353

\title{
PRESSURE DISTRIBUTION AND BUBBLE FORMATION INDUCED BY LONGITUDINAL VIBRATION OF \\ A FLEXIBLE LIQUID-FILLED CYLINDER
}

By

\author{
R. J. Schoenhals* \\ T. J. Overcamp ${ }^{* *}$
}

\section{SUMMARY}

Oscillating pressures in a plexiglas cylinder containing methanol were measured as it was vibrated parallel to its axis. Acceleration levels required to produce bubble formations and the locations of these formations were determined. These experimental results agree closely with predictions obtained from an analysis of the system. However, several discrepancies warrant further investigation.

\section{INTRODUCTION}

The interaction of fluid dynamics and flexible structures is of considerable practical interest in liquid propellant rocket technology. Cryogenic propellant storage tanks and lines are known to undergo severe longitudinal vibration during flight. Such an environment can give rise to two-phase fluid conditions (Ref. 1) that can seriously impede the performance of the propellant systems that are required to provide rapid fluid transfer (Ref. 2). This study was undertaken to develop an understanding of the onset of these two-phase conditions.

\footnotetext{
*Associate Professor, School of Mechanical Engineering, Purdue University, Lafayette, Indiana, NASA-ASEE Summer Faculty Fellowship Program, June-August 1965.

**NASA summer student employee, Michigan State University, East Lansing, Michigan.
} 
Time dependent pressures were predicted from an analysis of a flexible liquid-filled cylinder under the influence of longitudinal vibration. These predictions were compared with measurements obtained using a plexiglas cylinder containing methanol. Knowledge of the pressure distribution makes it possible to estimate the limiting conditions of vibration for which the fluid remains in the liquid state. Beyond these threshold conditions a two-phase fluid state is reached in which bubbles are formed. Results of the analysis were used to predict the vibration conditions required to produce bubbles and the locations of initial bubble formation. These predictions were compared with experimental measurements and observations.

This report is mainly concerned with dynamic conditions dominated by single-phase fluid behavior, and the results appear to be valid for vibration levels up to those required to bring about the onset of bubble formation.

\section{SURVEY OF LITERATURE}

A sketch of the system investigated is shown in FIG 1. Configurations such as this were previously studied by Bleich (Ref. 3). Bleich's investigation is fairly general, because two-dimensional effects are considered, and the effect of liquid compressiblity is included in the solution of one of the problems discussed. Ponder, Blount, and Fritz (Ref. 1) experimentally investigated the bubble formations induced by longitudinal vibration of plexiglas cylinders (FIG 2). The vibration level required to produce bubbles was determined as a function of frequency for several containers and for various liquid heights. The experimental and analytical predictions given in this report are in good agreement with the observations reported by Ponder et al.

Bleich (Ref. 4), Baird (Ref. 5) and Buchanan, Jameson, and Oedjoe (Ref. 6) studied the migration of gas bubbles in vibrating liquid columns. This phenomenon is of great interest in the study of twophase conditions.

The references cited here represent those which are most pertinent to the investigation. A comprehensive discussion of all the available literature related to this work would, of course, include many additional references. 
For ease of physical interpretation and comparison of predicted and experimental results, a one-dimensional model was analyzed. The following assumptions were imposed:

1. The fluid behavior is described in terms of longitudinal motion.

2. The fluid remains in the liquid phase with uniform properties throughout the volume.

3. Both the fluid and the flexible cylindrical container remain in the elastic range under the loads encountered.

4. Dissipative effects in the fluid and in the cylindrical wall are absent. ${ }^{1}$

5. The liquid remains in contact with the cylindrical wall at all times.

6. The deformation of each cross-section of the cylindrical wall is purely radial, and only the hoop stress generated by the local radial deformation is significant.

7. The cylindrical wall is thin, and its inertial effect is negligible.

8. Time dependent pressures in the liquid are not transmitted into the gas in the ullage space above the liquid. ${ }^{2}$

9. Inception of bubble formation occurs at a point in the liquid when the minimum instantaneous pressure occurring at that location decreases to a threshold value, $\mathrm{P}_{\mathrm{T}}$.

\footnotetext{
${ }^{1}$ The effect of damping is illustrated in Appendix B.

2 This assumption is easily justified on the basis of the large difference in the characteristic impedances (Ref. 7) of the liquid and gas phases, primarily because the density of the gas is very small in comparis on with that of the liquid.
} 
The equation of motion for the fluid (see Appendix A) is

$$
\frac{\partial^{2} Y}{\partial t^{2}}=C^{2} \frac{\partial^{2} Y}{\partial x^{2}}+g
$$

where $Y(x, t)$ is the longitudinal displacement of a circular crosssectional fluid layer at location $x$ from its equilibrium position under zero load conditions. The boundary conditions are

$$
-E_{X} \frac{\partial Y}{\partial x}(0, t)=P_{u}, \quad Y(L, t)=Y_{L} e^{i \omega t} .
$$

The solution of the wave equation (1) is composed of two components; a steady component, $Y_{0}(x)$, and an oscillating component, $Y_{1}(x, t)$, so that $Y(x, t)=Y_{0}(x)+Y_{1}(x, t)$. The equations and boundary conditions for $Y_{0}$ and $Y_{1}$ are .

$$
\begin{aligned}
& C^{2} \frac{d^{2} Y_{0}}{d x^{2}}+g=0 \\
& -E_{X} \frac{d Y_{0}}{d x}(0)=P_{u}, Y_{0}(L)=0,
\end{aligned}
$$

and

$$
\begin{aligned}
& \frac{\partial^{2} Y_{1}}{\partial t^{2}}=C^{2} \frac{\partial^{2} Y_{1}}{\partial x^{2}} \\
& -E_{X} \frac{\partial Y_{1}}{\partial x}(0, t)=0,1 \quad Y_{1}(L, t)=Y_{L} e^{i \omega t}
\end{aligned}
$$

Addition of equations (3) and (5) yields the original wave equation (1), and addition of the boundary conditions (4) and (6) gives results consistent with the original boundary conditions (2).

(5) and (6) gives

Adding the solution of equations ( 3 ) and (4) to that for equations

${ }^{\text {TThis }}$ condition is imposed in accordance with assumption 8. 


$$
Y(x, t)=\frac{P_{u}}{E_{X}}(L-x)+\frac{\rho g}{2 E_{X}}\left(L^{2}-x^{2}\right)+\left[Y_{L} \cdot \frac{\cos \frac{\omega x}{c}}{\cos \frac{\omega L}{c}}\right] e^{i \omega t}
$$

The pressure distribution is obtained from $P=-E_{X} \frac{\partial Y}{\partial X}$ which gives

$$
P(x, t)=P_{u}+\rho g x+\left[\operatorname{gg}_{L}\left(\frac{c}{\omega}\right) \frac{\sin \frac{\omega x}{c}}{\cos \frac{\omega L}{c}}\right] e^{i \omega t}
$$

where $g_{L}$ is the acceleration amplitude of the base. The steady component of pressure at any depth $x$ consists of two parts, the ullage pressure, $P_{u}$, and the hydrostatic pressure, $\rho g x$.

At very low frequencies $\left(\frac{\omega L}{c} \ll 1\right), \sin \frac{\omega x}{c} \rightarrow \frac{\omega x}{c}$ and $\cos \frac{\omega L}{c} \rightarrow 1$. For this condition the oscillating component of pressure, like the hydrostatic pressure, is linearly related to the depth and

$$
P=P_{u}+\rho\left(g+g_{L} e^{i \omega t}\right) x
$$

In this case the minimum instantaneous pressure at the bottom of the container approaches zero when $\frac{g_{L}}{g}=\left(1+\frac{P_{u}}{\rho g L}\right)$. The corresponding minimum instantaneous pressure at other points in the system is given by $P_{u}\left(1-\frac{x}{L}\right)$. It can be seen from this example that very low instantaneous pressures in the system are obtained only if $\frac{g_{L}}{g}$ exceeds unity. In addition, the lowest instantaneous minimum pressure occurs at the bottom of the container.

$$
\text { At higher frequencies }\left(\frac{\omega L}{c}>\frac{\pi}{2}\right) \text {, the amplitude of the oscillating }
$$

pressure is periodic in $x$, and the position of the lowest minimum instantaneous pressure moves upward from the cylinder base. For purposes of conciseness and generality, equation (8) is rewritten in dimensionless form as 


$$
\left[\frac{P-P u}{\rho g L}\right]=\frac{x}{L}+\left[\frac{G}{\Omega \cos \Omega} \sin \Omega \frac{x}{L}\right] e^{i \omega t}
$$

For cases in which the amplitude of the oscillating pressure has more than one maximum $\left(\Omega \geq \frac{3 \pi}{2}\right)$ the lowest minimum instantaneous pressure in the system occurs close to the point $\Omega \frac{x}{L}=\frac{\pi}{2}$, provided that $\left|\frac{G}{\cos \Omega}\right|$ is somewhat larger than unity. Minimum instantaneous pressures at points farther from the surface and close to other maxima of the amplitude term are larger due to the effect of the hydrostatic pressure (note the $\mathrm{x} / \mathrm{L}$ term in equation (10)).

For convenience the amplitude of the time varying pressure, $\Delta \mathrm{P}$, is obtained in dimensionless form from equation (10) as

$$
\left[\frac{\frac{\Delta P}{\rho g L}}{G}\right]=\left[\frac{\sin \Omega \frac{x}{L}}{\Omega \cos \Omega}\right]
$$

Resonance occurs for $\Omega=\frac{\pi}{2}, \frac{3 \pi}{2}, \frac{5 \pi}{2}, \ldots$, and infinite pressure amplitudes are predicted by equation (11) for these frequencies. This unacceptable result occurs due to assumption 4 and is prevented in the real physical system by the presence of friction and possibly by the non-linear behavior of the system under large deformations. These effects are not accounted for by equation (1), but are discussed in Appendix B.

To initiate bubble formation in a vibrating liquid, the local pressure level must be reduced to a sufficiently low value during a portion of the vibration cycle. For purposes of simplicity, it is assumed that bubbles will form at a particular location if the minimum instantaneous pressure falls below some threshold pressure value, $\mathrm{P}_{\mathrm{T}}$, (assumption 9).

For pure liquids it might be expected that $\mathrm{P}_{\mathrm{T}}$ would be close to the saturation pressure at the liquid temperature. This idea represents a considerable oversimplification. In reality the situation is far more complicated (Ref. 7) because the threshold pressure required to produce bubbles is dependent upon frequency, surface tension, dissolved gas properties, and a number of other factors. 
According to previous discussion in connection with equations (8) through (10), the minimum pressure, $P_{m}$, occurs at the bottom of the cylinder and is given by

$$
\frac{P_{u}-P_{m}}{p g L}=G\left(\frac{\tan \Omega}{\Omega}\right)-1
$$

for $\Omega<\frac{\pi}{2}$ provided that $G>1$. Similarly, for $\Omega>\frac{\pi}{2}$ the minimum pressure occurs close to $\dot{\Omega} \frac{x}{L}=\frac{\pi}{2}$ and is approximated by

$$
\frac{\mathrm{Pu}-\mathrm{Pm}}{\rho \mathrm{gL}} \approx\left|\frac{\mathrm{G}}{\Omega \cos \Omega}\right|-\frac{\frac{\pi}{2}}{\Omega}
$$

if $\frac{G}{|\cos \Omega|} \gg 1$.

The condition for inception of bubble formation in the system is obtained by setting $P_{m}=P_{T}$ in equations (12) and (13) which now are rewritten as

$$
G_{T}=\left[1+\left(\frac{P_{u}}{\rho g L}\right)\left(1-\frac{P_{T}}{P_{u}}\right)\right]\left(\frac{\Omega}{\tan \Omega}\right)
$$

and

$$
\mathrm{G}_{\mathrm{T}} \approx\left[\frac{\pi}{2}+\left(\frac{\mathrm{P}_{\mathrm{u}}}{\rho \mathrm{gL}}\right)\left(1-\frac{\mathrm{P}_{\mathrm{T}}}{\mathrm{P}_{\mathrm{u}}}\right) \Omega\right]|\cos \Omega| .
$$

$\mathrm{G}_{\mathrm{T}}$ represents the threshold acceleration level required to produce bubble formation. Equation (14) gives the acceleration level required to produce bubble formation at the bottom of the cylinder for $G>1$ when $\Omega<\frac{\pi}{2}$, while equation (15) gives the level required to produce bubbles close to $\frac{x}{L}=\frac{\pi}{2 \Omega}$ when $\Omega>\frac{\pi}{2}$ (provided that $\frac{G}{|\cos \Omega|} \gg 1$ ). 


\section{EXPERIMENTAL DETERMINATION OF OSCILLATING PRESSURES}

A plexiglas cylinder ( 4 -inch diameter by $3 / 8$-inch thick wall by 26 inches long) closed at its lower end was mounted on an electrodynamic shaker. Four pressure transducers were installed in the tube wall flush with the inner surface so that the liquid pressures could be measured. These transducers were installed at heights of 1 , 6,9 , and 12 inches from the base. A schematic diagram of the experimental apparatus is given in FIG 3.

Methanol was introduced into the cylinder, and the system was vibrated at levels low enough to prevent any bubble formations. The presence or absence of bubbles could be easily viewed due to the trans parency of the plexiglas container. When bubbles formed, the vibration was stopped until the bubbles disappeared. The vibration was then slowly increased, but was kept at a level low enough so that the bubbles did not reform. Thus, all of the measurements and observations discussed in this section are associated with vibration of a liquid column in the absence of bubbles.

The pressure signals were amplified and displayed on a four channel oscilloscope either simultaneously or one at a time. For making pressure amplitude measurements, the latter was more satisfactory, because higher gain could be used to expand a single pressure trace over a large part of the available range on the oscilloscope screen. The results of these measurements are shown in FIG $4 \mathrm{a}$ to $4 \mathrm{f}$ with the analytical predictions from equation (11). Liquid heights of 12,18 , and 24 inches were used to give a range of $x / L$ values for the four fixed probe positions.

All of the results show some scatter, a trend that became more pronounced as frequency increased. This can be partially attributed to the method of plotting the results for comparison with equation (11), which does not account for dissipation effects. No doubt other effects, not accounted for by the analysis, had their influence in the operation of the actual system from which the measurements were taken. For example, the one-dimensional longitudinal wave behavior (assumption 1) and the absence of wall inertia effects (assumption 7) give way to more complicated patterns of motion (Ref. 3 and 8 ) as frequency is increased. 
Under conditions of resonance, equation (11) predicts infinite pressure amplitudes. For these cases (FIG $4 \mathrm{~b}$ and $4 \mathrm{f}$ ), the analytically determined mode shapes are given, and the curves are labeled with the symbol $\infty$ to indicate tiat they are not drawn to scale. In botin cases the experimentally determined mode shapes are in agreement with the predicted ones.

For frequencies somewhat removed from resonant conditions (FIG 4a, c, $d$, and e), the measured pressure amplitudes tend to be larger than predicted. The deviation is fairly small for the lowest frequency illustrated (FIG 4a).

FIGURE 5 shows the simultaneous display of signals from the four pressure transducers as they appeared on the oscilloscope screen for the 18-inch high liquid column. Proceeding from top to bottom, the four pressure traces correspond to $x / L$ values of $0.33,0.50,0.67$, and 0.95. In FIG $5 \mathrm{a}$ the frequency is low enough so that all four signals are in phase (FIG $4 b$ ). FIG $5 b$ corresponds to a higher frequency $\left(\Omega=\frac{3 \pi}{2}\right)$. For this situation a pressure node occurs close to $\frac{x}{L}=0.67$ (FIG $4 f$ ). The two upper traces are in phase with each other while the third one indicates an extremely small pressure amplitude in accordance with its location close to the pressure node. The lower trace is $180^{\circ}$ out of phase with the upper two as would be expected from FIG $4 f$.

Since $\Omega=\omega \frac{L}{C}=2 \pi \frac{\mathrm{fL}}{\mathrm{C}}$, it was necessary to obtain the wave velocity $C$ for the particular system used in order to evaluate dimensionless frequency values for various combinations of vibration frequency and liquid column height. An estimate of the wave velocity can be obtained from the following approximate property values.

Density of Methanol (Ref. 9) $\approx 50 \mathrm{lb} / \mathrm{ft}^{3}$

Bulk Modulus of Methanol (Ref. 10 ) $\approx 1.86 \times 10^{5} \mathrm{psi}$

Modulus of Elasticity of plexiglas (Ref. 11$) \approx 2 \times 10^{5} \mathrm{psi}$

Based on these figures the sound velocity for methanol is $\sqrt{\frac{B}{\rho}}=4160 \mathrm{fps}$. However, the wave velocity, $C$, should be lower than this by a factor of $\sqrt{1+\frac{\mathrm{B}}{\frac{\mathrm{S}}{\mathrm{D}} \mathrm{E}}}$ in accordance with equation (A10). This leads to a calculated value of $C=1250 \mathrm{fps}$ for the experimental system used. 
Since the liquid bulk modulus and the modulus of elasticity of plexiglas are subject to considerable variation, the calculation given above should not be expected to yield a very reliable result in terms of the actual system performance. Because of this, $C$ was determined experimentally by varying the frequency until the first resonant mode was obtained $\left(\Omega=\frac{\pi}{2}\right)$. The mode shape was readily verified by means of the pressure signals (FIG 4b). The distinct increase in audible sound level within a very fine resonant frequency band made it possible to tune the system to this condition very easily. With $L=18^{\prime \prime}$, the frequency obtained was very close to $200 \mathrm{cps}$. Therefore, since $\Omega=2 \pi \frac{\mathrm{fL}}{\mathrm{C}}=\frac{\pi}{2}, \mathrm{C}=4 \mathrm{fL}=1200 \mathrm{fps}$ for the actual system. Thus, the previously calculated value of $1250 \mathrm{fps}$ provided a reasonably good estimate for $\mathrm{C}$.

In summary, the simplified analysis predicted the qualitative behavior exhibited by the experimental system. In addition, the order of magnitude of the calculated pressures is in agreement with the experimentally measured values (except for resonant conditions). However, a quantitative comparison of predicted and measured pressure amplitudes reveals a fairly large percentage of deviations between the two for some of the cases studied.

\section{OBSERVED BUBBLE FORMATIONS}

Initiation of bubble formation in a plexiglas cylinder containing methanol was investigated. For eacr. case observed, the vibration level was slowly increased until bubbles were sighted. The two major item: of interest were the location at which initial bubble formations occurred and the vibration level required to produce these formations. The results are discussed in terms of the simplified analytical model given previously.

FIGURES $6 \mathrm{a}$ and $6 \mathrm{~b}$ illustrate system behavior that was typical at the lower frequencies. According to the simplified analytical model, bubbles would be expected to form initially at the cylinder bottom. This did occur, but it was often accompanied by considerable bubble formation at the liquid surface when sloshing was present. These bubbles migrated rapidly to the bottom after formation. The upper bubble 
formation region usually would propagate downward, slowly at first and then very rapidly. FIGURE 6 a shows initial bubble formations occurring simultaneously at the bottom (since the pressure amplitude was largest there - see FIG 4a) and at the top due to sloshing. FIGURE 6b shows the rapid growth of these formations that accompanied the violent downward movement of the upper bubble formation region. Although bubble formation at the bottom is predicted by the simplified analytical model, sloshing and bubble formation at the top are not. This complicated surface phenomenon, which occurred at low frequencies in the present investigation, is in agreement with some of the observations reported by Bleich and by Buchannan, et al.

FIGURES 6c, 6d, and 6e show typical initial bubble formations at $\frac{x}{L}$ values close to $1.0,0.5$ and 0.33 for $\Omega=\frac{\pi}{2}, \pi$ and $\frac{3 \pi}{2}$, respectively. These are the locations of maximum pressure amplitude (FIG $4 \mathrm{~b}, 4 \mathrm{~d}$ and 4f) and minimum instantaneous pressure, $P_{m}$, for these frequencies according to the simplified analytical model.

When $\Omega=\frac{3 \pi}{2}$, there are two locations having the same predicted maximum pressure amplitude (FIG 4f), $\frac{x}{L}=0.33$ and $\frac{x}{L}=1.0$. However, the predicted minimum instantaneous pressure, $\mathrm{P}_{\mathrm{m}}$, in the system occurs at the upper location, because the hydrostatic pressure is lower there than at the bottom. This can be verified from equation (10) which contains a hydrostatic component of pressure proportional to depth below the surface. Since the predicted minimum system pressure occurs close to $\frac{x}{L}=0.33$, it would be expected that bubbles would form at that location first, and not at the bottom. This was confirmed in several experiments duplicating these conditions, and the formation of one or two small bubbles at $\frac{x}{L}=0.33$ usually occurred as illustrated in FIG $6 \mathrm{e}$.

On the other hand, the magnitude of the hydrostatic pressure was fairly small for the system observed in the present investigation, and the apparent preferential location of $\frac{x}{L}=0.33$ as opposed to $\frac{x}{L}=1.0$ did not always dominate. Occasionally initiation of bubble formation occurred simultaneously at both locations. Only once did bubbles appear at the bottom before any bubble activity was sighted at 
$\frac{x}{L}=0.33$; however, a single small bubble formed at $\frac{x}{L}=0.33$ and started to rise to the surface just as the system was photographed (FIG 6f). The two bubble formations at the bottom, which actually formed first, are clearly visible. The smaller bubble rising toward the surface is not as noticeable.

It was concluded from the many observations made for $\Omega=\frac{3 \pi}{2}$ that the hydrostatic pressure effect caused the upper pressure amplitude maximum to be the preferred location for initial formation of bubbles. However, this hydrostatic effect was small and did not always prevent initial bubble formation at the location of the lower pressure amplitude maximum (at the cylinder bottom).

The photographs in FIG 6 a through $6 f$ indicate how the location of initial bubble formations is affected by variations in frequency. The threshold acceleration level, $G_{T}$, was obtained with the same system by slowly increasing the vibration level until bubbles were sighted. At this point the acceleration level was read from the vibration meter (FIG 3). The experimental results obtained are comparable to previously reported data (Ref. 1) and are plotted in FIG 7 and 8. For the system used in making these observations, the ratio of ullage pressure (atmospheric) to hydrostatic pressure at the cylinder base was $\frac{P_{u}}{\rho g L}=25$.

FIGURE 7 shows a comparison of the data with the analytical prediction for the low frequency range. The analytical result was plotted using equations (14) and (15). It was assumed that the threshold pressure, $P_{T}$, was equal to the fluid saturation pressure, $P_{S}$, (Ref. 9) for the ambient temperature conditions existing at the time the experiments were conducted. This gave $\frac{\mathrm{P}_{\mathrm{T}}}{\mathrm{P}_{\mathrm{u}}}=\frac{\mathrm{P}_{\mathrm{S}}}{\mathrm{P}_{\mathrm{u}}}=0.2$, and $\frac{\mathrm{P}_{\mathrm{u}}}{\rho \mathrm{gL}}\left(1-\frac{\mathrm{P}_{\mathrm{T}}}{\mathrm{P}_{\mathrm{u}}}\right)=$ $25(1-0.2)=20$. The latter value was inserted into equations (13) and (14) to generate the plot indicated by the solid line in FIG 7. Both the predicted and experimental $\mathrm{G}_{\mathrm{T}}$ curves drop sharply in the vicinity of the first resonant frequency $\left(\Omega=\frac{\pi}{2}\right)$ while exhibiting larger values on either side of this frequency. The experimental curve does not reach a zero threshold value as does the analytical curve because of damping in the system. This effect was not accounted for in the simplified analytical model (assumption 4 ) which predicted a zero value for $G_{T}$ 
at resonance. In view of the method used to generate the predicted $\mathrm{G}_{\mathrm{T}}$ curve, the agreement of this result with the experimental data is considered very favorable in the low frequency range.

For frequencies somewhat in excess of $\Omega=\frac{\pi}{2}$, the analytical prediction gave results considerably larger than the experimentally measured $G_{T}$ values if $P_{T}$ were assumed equal to $P_{S}$. This deviation had been expected, because it was not realistic to presume that threshold pressure is dominated by the fluid saturation pressure for all values of frequency, particularly since the liquid used for the experiments was not degassed. The bubbles that formed contained large amounts of previously dissolved gas. This was apparent because the bubbles would rise slowly to the surface due to buoyancy following immediate termination of vibration after the bubbles had formed. Vapor bubbles would have collapsed instantly.

Experimental data obtained over a wide frequency range are given in FIG 8. A plot of results obtained from the analytical model is also shown. This plot was made using equations (14) and (15) with a value of 15 for $\left(\frac{P_{u}}{\rho g L}\right)\left(1-\frac{P_{T}}{P_{u}}\right)$. With $\frac{P_{u}}{\rho g L}=25$, this corresponds to $\frac{\mathrm{P}_{\mathrm{T}}}{\mathrm{P}_{\mathrm{u}}}=0.4$ and a threshold pressure of about $5.7 \mathrm{psi}$. The choice of this single threshold pressure level (approximately twice the fluid saturation pressure) is somewhat arbitrary since $\mathrm{P}_{\mathrm{T}}$ in reality is probably frequency dependent as mentioned above. However, the use of a fixed $P_{\mathrm{T}}$ value to obtain a single analytically derived curve makes it easier to compare results of the analysis with data obtained experimentally.

1 A smaller value of $\frac{\mathrm{P}_{\mathrm{T}}}{\mathrm{P}_{\mathrm{u}}}$ fits the experimental data better up to $\Omega=\frac{\pi}{2}$ as shown in FIG 7 , and a slightly larger value of $\frac{P_{T}}{P_{u}}$ would produce more of a favorable comparison for $\Omega$ greater than $\frac{\pi}{2}$. 
The similarities in the predicted and experimentally obtained $\mathrm{G}_{\mathrm{T}}$ curves are apparent in FIG 8. Both undergo distinct decreases at the two resonant frequencies, $\Omega=\frac{\pi}{2}$ and $\frac{3 \pi}{2}$, and exhibit larger values on either side of these two frequencies. Due to damping, the experimental curve never reaches a zero threshold value. The analytical curve, on the other hand, touches the horizontal axis at both resonant frequencies. The experimental curve is considerably below the analytical curve from $\Omega=2.5$ to 4 . This is in agreement with the fact that measured pressure amplitudes in this range were generally larger than those predicted by the analytical model (FIG 4c and 4d). Another factor that may explain the deviation in this range is that the actual threshold pressure of the fluid may vary considerably with frequency, as was previously mentioned.

The distinct dip in the experimental $\mathrm{G}_{\mathrm{T}}$ curve in the vicinity of $\Omega=\pi$ does not agree with the trend predicted from the analysis. Possible explanations are:

(a) The simple one-dimensional analytical model may not be very accurate in this frequency range.

(b) The damping properties of the plexiglas container may have undergone severe variations within this small frequency range in a manner which is typical of some polymers (Ref. 12).

(c) The actual threshold pressure of the fluid may vary significantly in this frequency range.

Further effort is needed to determine which of the above possibilities, or other contributing factor not listed here, is responsible for the behavior of the observed experimental system in the region close to $\Omega=\pi$.

In summary, it was concluded that, except for the surface phenomena occurring in the low frequency range, the locations of initial bubble formations were predicted reasonably well. The predicted threshold acceleration levels produced results corresponding to the measured values with respect to order of magnitude as well as a significant portion of the general qualitative trends. Very good correlation with experimental data was obtained at low frequencies 
when the analytical prediction was based on a threshold pressure equal to the fluid saturation pressure. At higher frequencies, however, the quantitative predictions from the analytical model were dependent. upon the uncertain choice of an appropriate value of threshold pressure, and the prediction of pressure amplitudes was not as accurate. Only one very distinct trend exhibited by the measured data was not predicted by the analytical model.

\section{CONCLUSIONS AND RECOMMENDATIONS}

In this study many of the experimental observations correlated reasonably well with results obtained from an analysis of the system. Certain discrepancies remain, however, and to explain them additional experimental data as well as more extensive analyses are required. 


\section{APPENDIX A \\ DERIVATION OF EQUATION OF MOTION}

Consider an element of the system as shown in FIG 9. A force balance on the cylindrical wall gives

$$
P D d x=2 \sigma s d x
$$

For an elastic wall, $\sigma=E \varepsilon$, where $\varepsilon$ is the circumferential strain of the wall. If $\Delta \mathrm{D}$ represents the increase in diameter due to pressure, $P$, then $\varepsilon=\frac{\Delta(\pi D)}{\pi D}=\frac{\Delta D}{D}$. Equation (Al) now can be rewritten as

$$
\Delta \mathrm{D}=\frac{\mathrm{D}^{2} \mathrm{P}}{2 \mathrm{sE}} \text {. }
$$

Now consider a thin cylindrical slice of fluid of length, $\boldsymbol{l}$, and volume, $\mathrm{V}=\frac{\pi}{4} \mathrm{D}^{2} l$. For small deformations the change in volume of the fluid element due to pressure, $P$, is given by

$$
\Delta \mathrm{V}=\frac{\pi}{4} \mathrm{D}^{2} \ell\left(\frac{\Delta \ell}{\ell}+2 \frac{\Delta \mathrm{D}}{\mathrm{D}}\right)=-\frac{\mathrm{P}}{\mathrm{B}} \mathrm{V} .
$$

Combining equations (A2) and (A3) gives the longitudinal strain of the fluid as

$$
\varepsilon_{\mathrm{x}} \equiv \frac{\Delta \ell}{\ell}=-\frac{\mathrm{P}}{\mathrm{E}_{\mathrm{x}}}
$$

where $E_{\mathbf{X}}$, the effective longitudinal modulus of elasticity of the fluid column, is defined as

$$
\mathrm{E}_{\mathrm{X}} \equiv \frac{\mathrm{B}}{\left[1+\frac{\mathrm{B}}{\left(\frac{\mathrm{s}}{\mathrm{D}}\right) \mathrm{E}}\right]}
$$

Thus, the longitudinal stiffness of the column is dependent upon the stiffness, B, of the fluid and the stiffness of the cylindrical container, 
$\frac{S}{D} E$. The ratio of the longitudinal stiffness to the fluid stiffness is less than unity in general and is given by $\frac{E_{x}}{B}=r=\left[\frac{1}{1+\frac{B}{\left(\frac{s}{D} E\right)}}\right]$.

The displacement of a cross-sectional fluid element from its equilibrium position under zero load is $Y(x, t)$. The local longitudinal strain is $\varepsilon_{X}=\frac{\partial Y}{\partial X}$, and in accordance with equation (A4), the pressure of the fluid is $P=-E_{x} \frac{\partial Y}{\partial X}$. The instantaneous velocity of the element is $\frac{\partial Y}{\partial t}$, and its acceleration is $\frac{\partial^{2} Y}{\partial t^{2}}$. Newton's law is written as

$$
\rho A d x \frac{\partial^{2} Y}{\partial t^{2}}=F_{x}
$$

where $F_{x}$ is the net force on the element in the $x$ direction. FIGURE 10 shows the forces acting on a fluid element. Since $P$ may vary with $x$, the diameter of the cylindrical container may vary also, and a longitudinal component of force is generated by the tapered cylindrical wall. This longitudinal component is $\mathrm{P} \pi \mathrm{D} d z \sin \alpha$. Now, $\sin \alpha=$ $\frac{1}{2}\left(\frac{\partial D}{\partial x}\right)\left(\frac{d x}{d z}\right)=\frac{1}{\pi D}\left(\frac{\partial A}{\partial x}\right)\left(\frac{d x}{d z}\right)$, so the tube wall longitudinal component becomes $P\left(\frac{\partial A}{\partial x}\right) d x$. The net force in the $x$ direction is

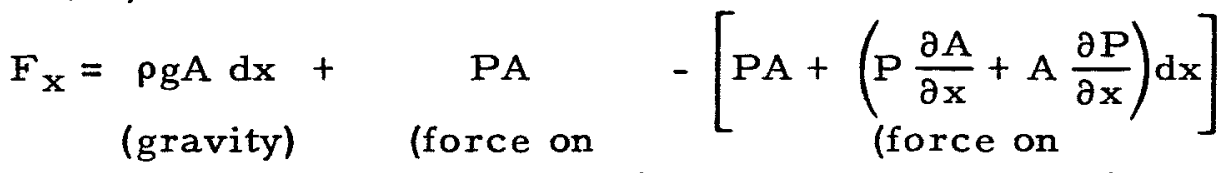

$$
\begin{aligned}
& \text { upper surface) lower surface) } \\
& +\quad \mathrm{P} \frac{\partial \mathrm{A}}{\partial \mathrm{x}} \quad=\rho \mathrm{Adx}\left[\mathrm{g}-\frac{1}{\rho} \frac{\partial \mathrm{P}}{\partial \mathrm{x}}\right] \text {. }
\end{aligned}
$$

Entering $P=-E_{X} \frac{\partial Y}{\partial x}$ into equation (A7) and inserting the resulting expression for $F_{x}$ into equation (A6) gives

$$
\underset{\text { (inertia effect) }}{\frac{\partial^{2} Y}{\partial t^{2}}}=\underset{C^{2} \frac{\partial^{2} Y}{\partial x^{2}}}{\text { (elastic force) }} \quad+\underset{\text { (gravity force) }}{ }
$$


This is the wave equation where $C=\sqrt{\frac{E_{x}}{\rho}}$ is the longitudinal wave velocity of the system.

Note that the wave velocity, $C$, is considerably less than the fluid acoustic velocity $\left(a=\sqrt{\frac{B}{\rho}}\right)$ when the fluid stiffness, $B$, is significantly greater than the wall stiffness, $\frac{\mathrm{s}}{\mathrm{D}} \mathrm{E}$. This can be seen by inserting the expression for $E_{X}$ into the relation for $C$ which gives

$$
C=\frac{a}{\sqrt{1+\frac{B}{\left(\frac{s}{D} E\right)}}}
$$




\section{APPENDIX B}

\section{FURTHER DETAILS OF SYSTEM BEHAVIOR}

Dissipation of energy can occur in the fluid due to viscosity and in the cylindrical wall due to viscoelastic behavior. For conditions encountered in this investigation, the fluid viscous boundary layer is very thin. ${ }^{1}$ The core velocity, $U$, is equivalent to $\frac{\partial Y}{\partial t}$ in terms of previously used notation. It is valid to neglect convective terms (of the order of $U \frac{\partial U}{\partial x}$ ) in comparison with local accelerations (of the order of $\left.\frac{\partial U}{\partial t}\right)$ if

$$
\mathrm{U}_{\mathrm{m}}\left(\frac{\mathrm{U}_{\mathrm{m}}}{\frac{\lambda}{4}}\right) \ll \omega \mathrm{U}_{\mathrm{m}}
$$

where $U_{m}$ is the maximum core velocity amplitude in the system. Since $\left(\frac{\omega}{2 \pi}\right) \lambda=C$, the above inequality can be rewritten as $U_{m} \ll \frac{\pi C}{2}$.

The result of the order of magnitude analysis carried out above implies that convective momentum effects in the fluid are unimportant if the longitudinal wave velocity is considerably greater in magnitude than the longitudinal fluid velocity oscillations. This condition was easily fulfilled in all of the experiments carried out. In view of this approximation the boundary layer (Ref. 13) momentum equation is

$$
\frac{\partial u}{\partial t}=\frac{\partial U}{\partial t}+v \frac{\partial^{2} u}{\partial y^{2}}
$$

where $u$ is the longitudinal velocity in the boundary layer.

The oscillation boundary layer thickness, or depth of penetration (Ref. 13) as it is sometimes referred to, is calculated from $\delta_{0}=\sqrt{\frac{\nu}{\omega}}$. For methanol the viscosity at room temperature is about 0.55 centipoises. Since the density is $50 \mathrm{lb} / \mathrm{ft}^{3}$ (Ref. 9), the kinematic viscosity $v$ is $0.74 \times 10^{-5} \mathrm{ft}^{2} / \mathrm{sec}$. Entering this value into the expression for $\delta_{0}$ gives $\delta_{0}=0.001$ inch for a frequency of $170 \mathrm{cps}$. 
Now, the oscillating portion of the longitudinal core motion is written as $Y_{I}(x, t)=M^{*}(x) e^{i \omega t}$. Also, $U=\frac{\partial Y_{1}}{\partial t}=i \omega M^{*} e^{i \omega t}$. In a similar manner the boundary layer velocity for a given value of $x$ is written as $u=N^{*}(y) e^{i \omega t}$. Equation (Bl), written in complex notation, is

$$
\frac{\mathrm{d}^{2} \mathrm{~N}^{*}}{\mathrm{dy^{2 }}}-\left(\mathrm{i} \frac{\omega}{v}\right) \mathrm{N}^{*}=\left(\frac{\omega^{2}}{v}\right) \mathrm{M}^{*}
$$

The solution is

$$
N^{*}=i \omega M^{*}+C_{1} \exp \left(-y \sqrt{\frac{i \omega}{v}}\right)+C_{2} \exp \left(y \sqrt{\frac{i \omega}{v}}\right)
$$

As y becomes large, $\mathrm{N}^{*}$ must approach $\mathrm{i} \omega \mathrm{M}^{*}$, so $\mathrm{C}_{2}=0$. If the longitudinal motion of the cylindrical wall follows that of the base, then the wall velocity is given by $i \omega Y_{L} e^{i \omega t}$. The fluid velocity at the wall is the same, and therefore, $i \omega M^{*}+C_{1}=i \omega Y_{L}$. With $C_{1}$ and $C_{2}$ determined, equation (B3) is rewritten as

$$
N^{*}=i \omega M^{*}+i \omega\left(Y_{L}-M^{*}\right) \exp \left(-\sqrt{i} \frac{y}{\delta_{0}}\right)
$$

where $\delta_{0}$ is the oscillation boundary layer thickness $\sqrt{\frac{\nu}{\omega}}$.

The wall shear stress, $T$, is obtained by differentiating equation (B4) and evaluating $-\mu \frac{\partial u}{\partial y}$ at $y=0$. The result, written in complex notation, is

$$
T^{*}=(i)^{3 / 2}\left(\frac{\mu \omega}{\delta_{0}}\right)\left(Y_{L}-M^{*}\right)
$$

Equation (A7) is now modified to include the shear force acting on the fluid at the wall. The net force becomes

$$
F_{x}=\rho A d x\left(g-\frac{1}{\rho} \cdot \frac{\partial P}{\partial x}\right)+\tau \pi D d x
$$

The last term in this equation is obtained from equation (B5).

To account for viscoelastic behavior, the complex modulus of elasticity (Ref. 12) of the cylinder wall is written as $E^{*}=E^{\prime}+i E^{\prime \prime}$. 
For small amounts of damping the real portion is essentially the same as the ordinary modulus of elasticity. In this case $E^{*}=E(1+i \phi)$ where $\phi$ is the loss factor $\frac{E^{\prime \prime}}{E^{\prime}}$. The oscillating components of stress and strain are obtained from the development given in Appendix $A$, but with $E$ replaced by $E^{*}$ to account for the damping effect.

Equation (A5) is rewritten as

$$
E_{X^{*}} \frac{B}{i+\frac{B}{\frac{s}{D} E^{*}}}=\left(\frac{1+i \phi}{1+i r \phi}\right) E_{X} \text {. }
$$

The oscillating component of force is obtained from equation (B6) and is equated to the inertia term as in equation (A6). With $Y_{1}(x, t)$ expressed as $M^{*}(x) e^{i \omega t}$, the result is

$$
\rho A d x(i \omega)^{2} M^{*}=-A d x \frac{d}{d x}\left(-E_{x} * \frac{d M}{d x}\right)+T^{*} \pi D d x .
$$

Inserting $\tau^{*}$ from equation (B5) gives

$$
C * \frac{d^{2} M^{*}}{d x^{2}}+\omega^{2} M^{*}+4(i)^{3 / 2}\left(\frac{\delta_{0}}{D}\right) \omega^{2}\left(Y_{L}-M^{*}\right)=0
$$

where $C^{*}=\sqrt{\frac{E_{x}^{*}}{\rho}}$, the complex wave velocity of the system. Note that the last term is negligibly small when $\frac{\delta_{0}}{D} \ll 1$, provided that $M^{*}$ is the same order of magnitude as $\mathrm{Y}_{\mathrm{L}}$. For experiments carried out in this investigation, $\frac{\delta_{0}}{\mathrm{D}}$ was of the order of $10^{-3}$. It is concluded, therefore, that the damping effect due to viscous fluid shear at the wall was very small. 1 For this reason the last term in equation (B9) is neglected. The solution for the complex pressure amplitude follows essentially the same procedure as was used in obtaining equation (11). The result is identical in form and is written as

There is another source of energy dissipation associated with viscous action in the core of the fluid due to its periodic campression and expansion. In the present study this effect was found to have a magnitude even smaller than that of the wall friction. 


$$
\frac{\frac{\Delta P^{*}}{\rho g L}}{G}=\frac{\sin \Omega^{*} \frac{x}{L}}{\Omega^{*} \cos \Omega^{*}} .
$$

In this formulation the oscillating pressure is given by $\Delta \mathrm{P}^{*} \mathrm{e}^{\mathrm{i} \omega \mathrm{t}} \cdot \Omega^{*}$ is the dimensionless complex frequency defined as $\frac{\omega \mathrm{L}}{\mathrm{C} *}$. Using the expression given in equation (B7), it can be shown that $\Omega^{*}=\Omega \sqrt{\frac{1+i r \phi}{1+i \phi}}$.

The magnitude of the pressure oscillations is obtained from equation (BlO) and is written as

$$
\frac{\left|\frac{\Delta \mathrm{P}^{*}}{\rho \mathrm{gL}}\right|}{\mathrm{G}}=\left|\frac{\sin \left(\Omega \sqrt{\frac{1+\mathrm{ir} \phi}{1+\mathrm{i} \phi}} \frac{\mathrm{x}}{\mathrm{L}}\right)}{\Omega \sqrt{\frac{1+\mathrm{ir} \phi}{1+\mathrm{i} \phi}} \cos \left(\Omega \sqrt{\frac{1+\mathrm{ir} \phi}{1+\mathrm{i} \phi}}\right)}\right| \text {. }
$$

For the experimental system used in making the pressure measurements, $r$ was approximately 0.10 . Although the damping properties of plexiglas are subject to considerable variation, a loss factor of 0.05 appears to be a reasonable value (Ref. 15) at room temperature for the frequency range investigated.

A plot of equation (BI1) is shown in FIG 11 for $\frac{x}{L}=0.5$ with $r=0.10$ and $\phi=0.05$. Predicted pressure amplitudes at the resonant frequencies are large, but finite. The limited amount of experimental data shown correlates reasonably well with the prediction. In the absence of energy dissipation $(\phi=0)$ equation (Bll) is identical to equation (11), and infinite resonant pressure amplitudes are predicted. This unacceptable result illustrates the necessity for including dissipation effects in any complete analysis of the system. Otherwise, realistic predictions in the resonant ranges of frequency cannot be obtained.

To obtain the threshold acceleration levels, it is possible to develop relations equivalent to equations (14) and (15) that include dissipation effects. It was found, however, that a more straightforward procedure could be carried out using a computer printout of equation (B 1 1). The expression for pressure is first written in a form similar to that of equation (10): 


$$
\frac{P-P_{u}}{\rho g L}=\frac{x}{L}+\left(\frac{\Delta P^{*}}{\rho g L}\right) e^{i \omega t}
$$

The minimum pressure in the system is equal to $\mathrm{P}_{\mathrm{T}}$ at the threshold condition. This results in

$$
\frac{P_{T}-P_{u}}{P g L}=\frac{x}{L}-\frac{\left|\Delta P^{*}\right|}{P g L}
$$

where the $\frac{x}{L}$ value corresponds to the location of minimum pressure. Rearrangement of equation (B13) gives

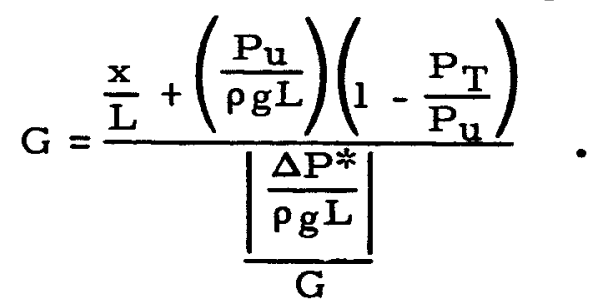

The threshold condition corresponds to the position producing the lowest value of $G$ from equation (B14). For $\left(\frac{P_{u}}{\rho_{g} L}\right)\left(1-\frac{P_{T}}{P_{u}}\right) \gg 1$, this occurs very close to the location where the denominator of equation (B14) is a maximum. If this position is denoted by $\left(\frac{x}{L}\right)_{m}$, then

$$
\mathrm{G}_{\mathrm{T}} \approx \frac{\left(\frac{\mathrm{x}}{\mathrm{L}}\right)_{\mathrm{m}}+\left(\frac{\mathrm{Pu}_{\mathrm{u}}}{\rho \mathrm{gL}}\right)\left(1-\frac{\mathrm{P}_{\mathrm{T}}}{\mathrm{P}_{\mathrm{u}}}\right)}{\left(\frac{\left|\frac{\Delta \mathrm{P}^{*}}{\rho \mathrm{gL}}\right|}{\mathrm{G}}\right)_{\text {maximum }}}
$$

Inspection of a computer printout of equation (BII) gave the maximum values of $\frac{\left|\frac{\Delta P^{*}}{\rho g L}\right|}{G}$ and the $\left(\frac{x}{L}\right)_{m}$ locations. Inserting these values into equation (B15) gave the corresponding threshold acceleration levels. The result of this prediction is shown in FIG 12 for 
$\left(\frac{\mathrm{P}_{\mathrm{u}}}{\rho \mathrm{gL}}\right)\left(1-\frac{\mathrm{P}_{\mathrm{T}}}{\mathrm{P}_{\mathrm{u}}}\right)=15$, the same value that was used in plotting the result shown in FIG 8. However, in this case energy dissipation is accounted for $(r=0.10, \phi=0.05)$. The predicted $G_{T}$ values at resonance are non-zero in agreement with the behavior of the experimental data. Despite the improvement, predicted $\mathrm{G}_{\mathrm{T}}$ values are still low at resonance. Also, the predicted values remain somewhat greater than the measured values in the range of $\Omega=2.5$ to 4 . Thus, based on realistic values of the properties of plexiglas, accounting for the presence of energy dissipation does not remove the discrepancy in this frequency range (FIG 8 and 12 ).

In this appendix certain improvements were obtained in the predicted results by accounting for viscous energy dissipation. The most significant improvements, with respect to the simplified analytical model, were obtained at the near resonant frequencies. Certain discrepancies between predicted and measured results, somewhat removed from the fundamental longitudinal resonances of the system, remain to be explained. 


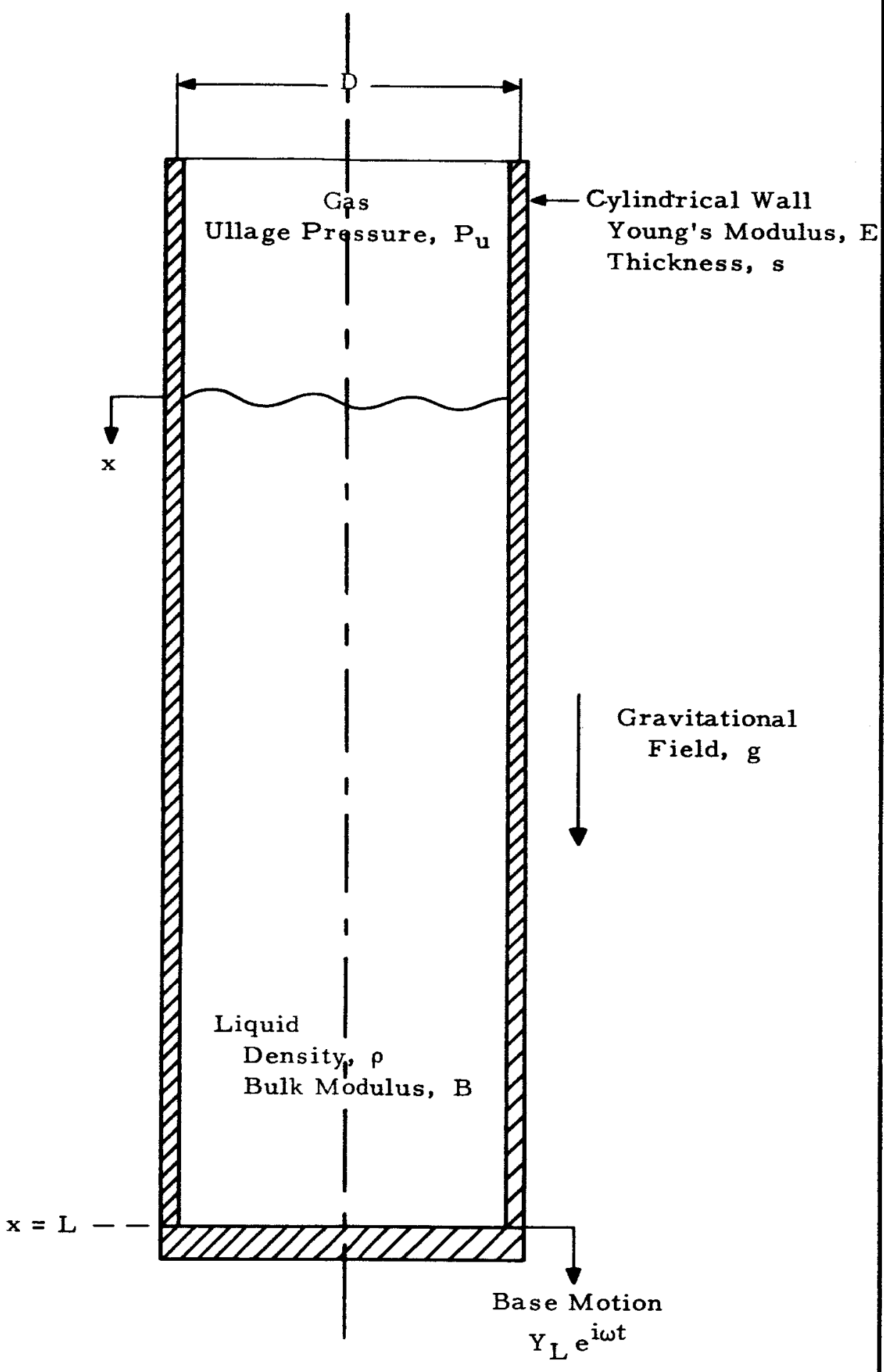

FIG. 1 LONGITUDINAL VIBRATION OF A FLEXIBLE LIQUID-FILLED CYLINDER 


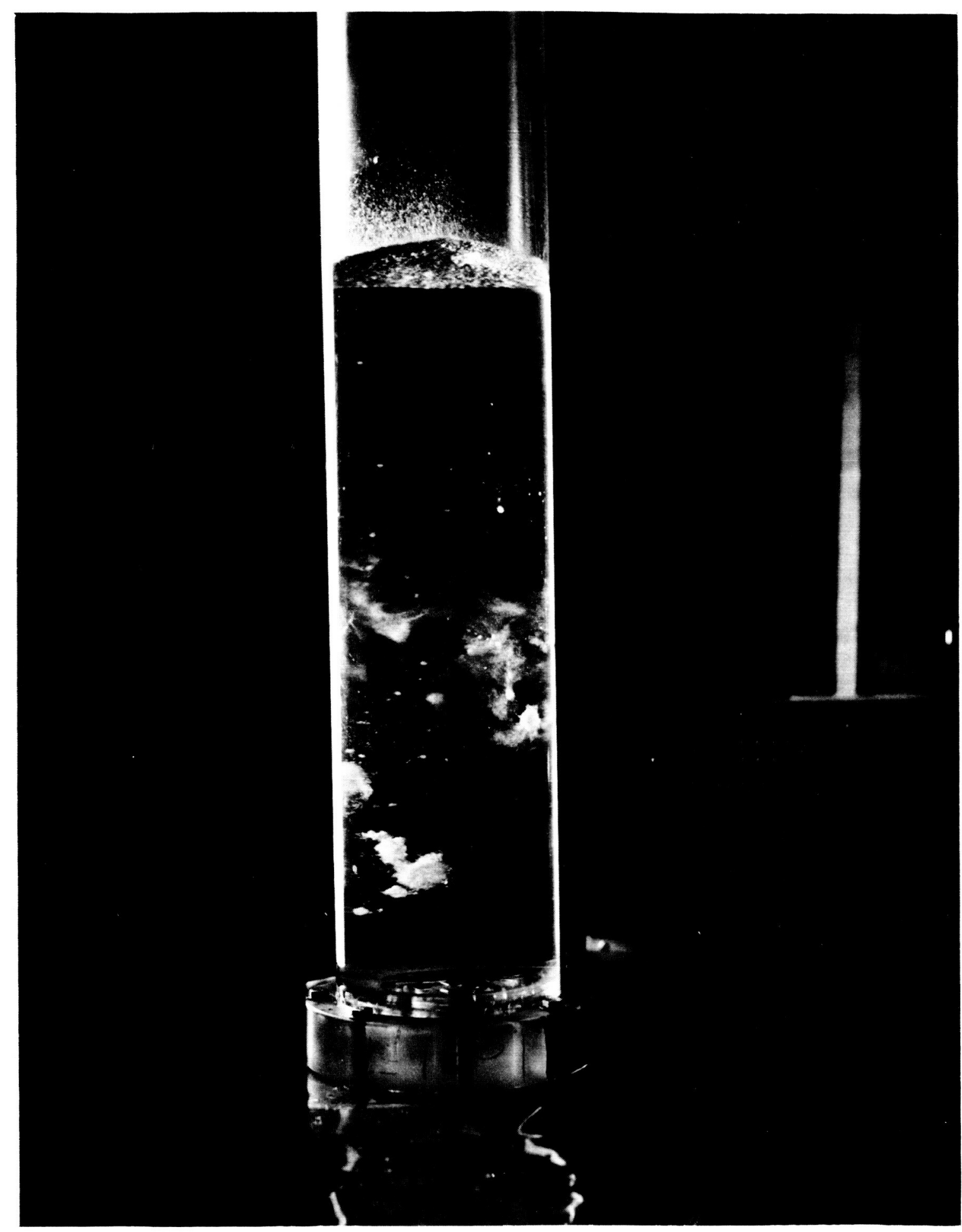

FIGURE 2. BUBBLE FORMATIONS IN A VIBRATING LIQUID. (Reference 1) 


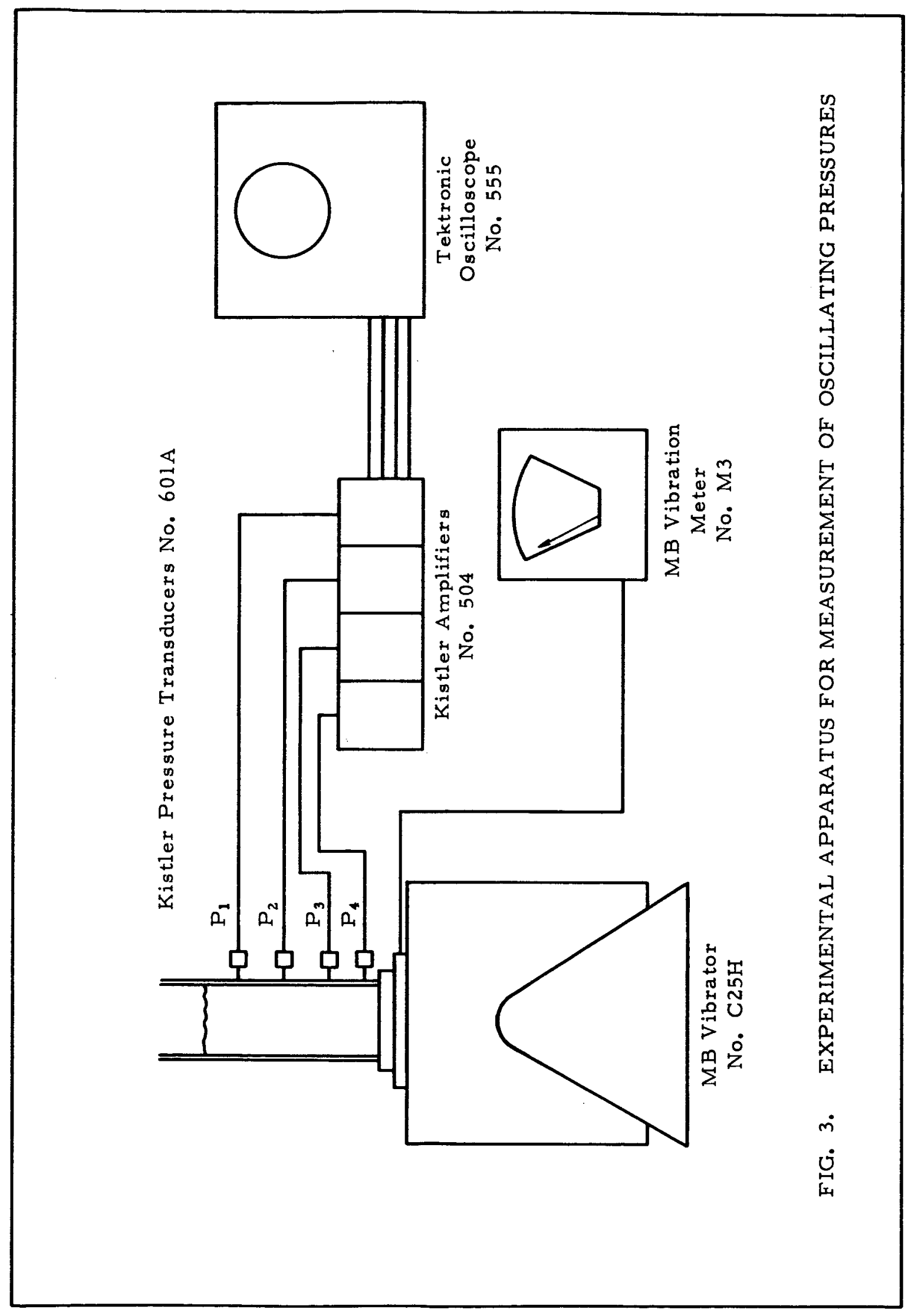




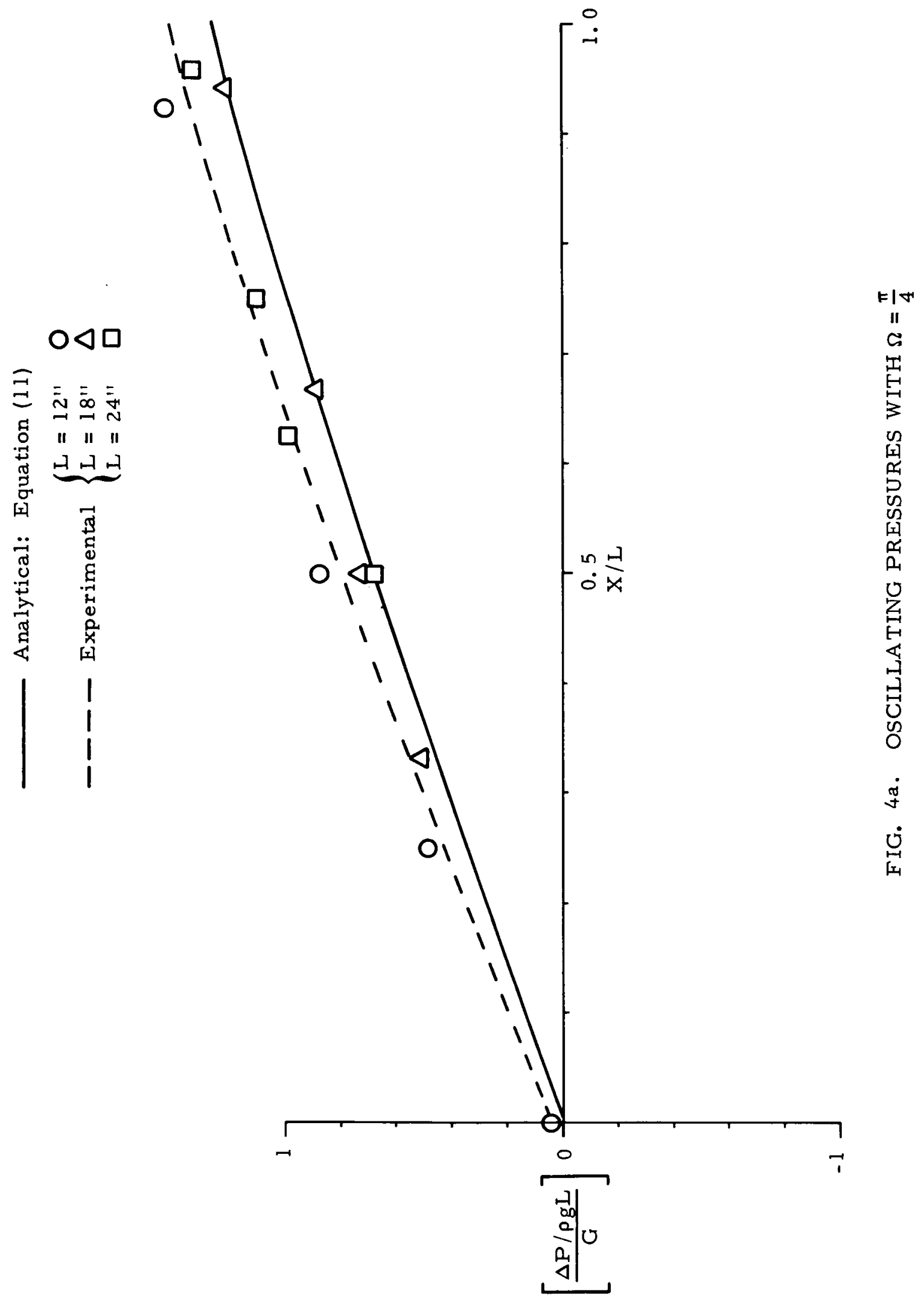




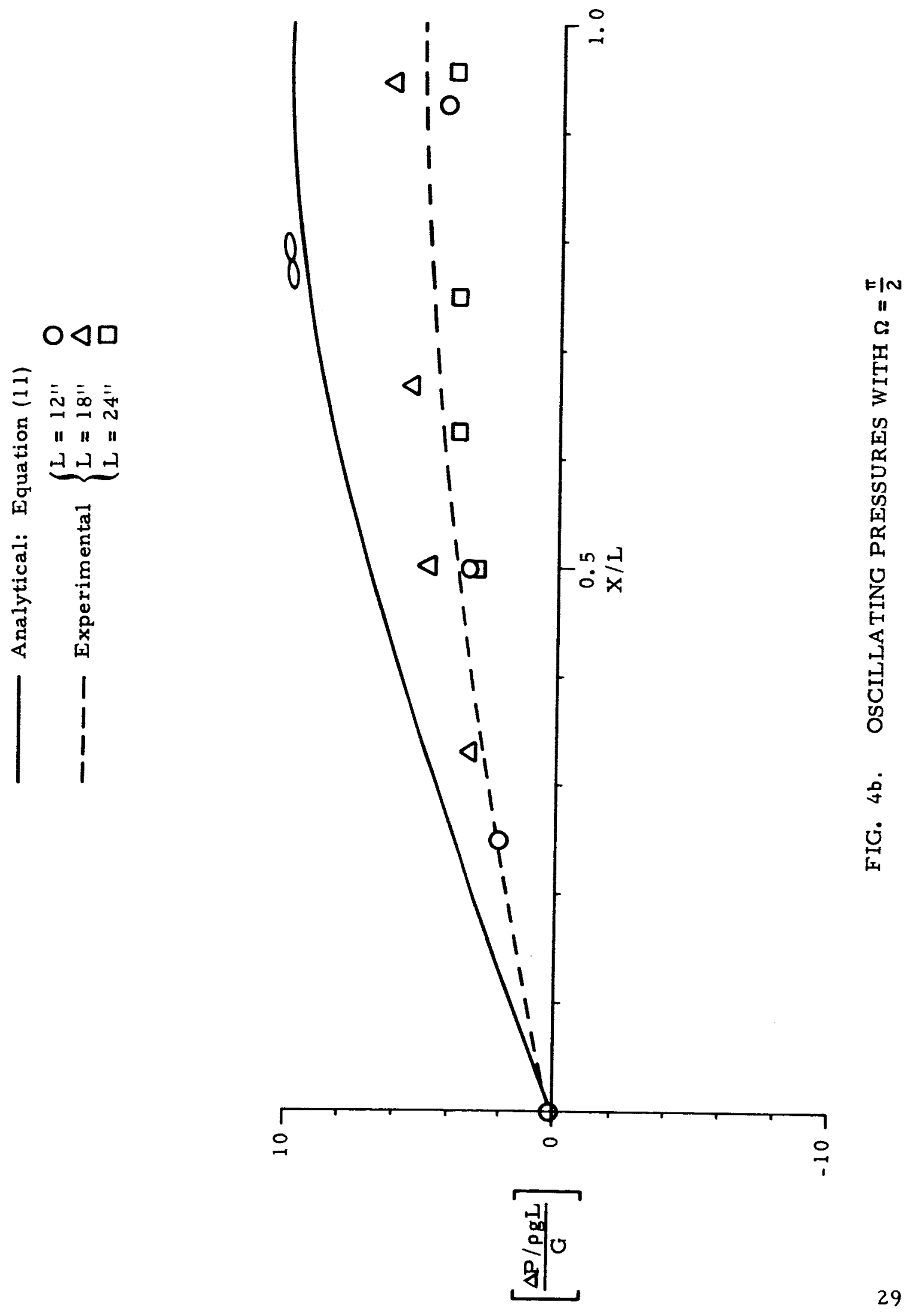




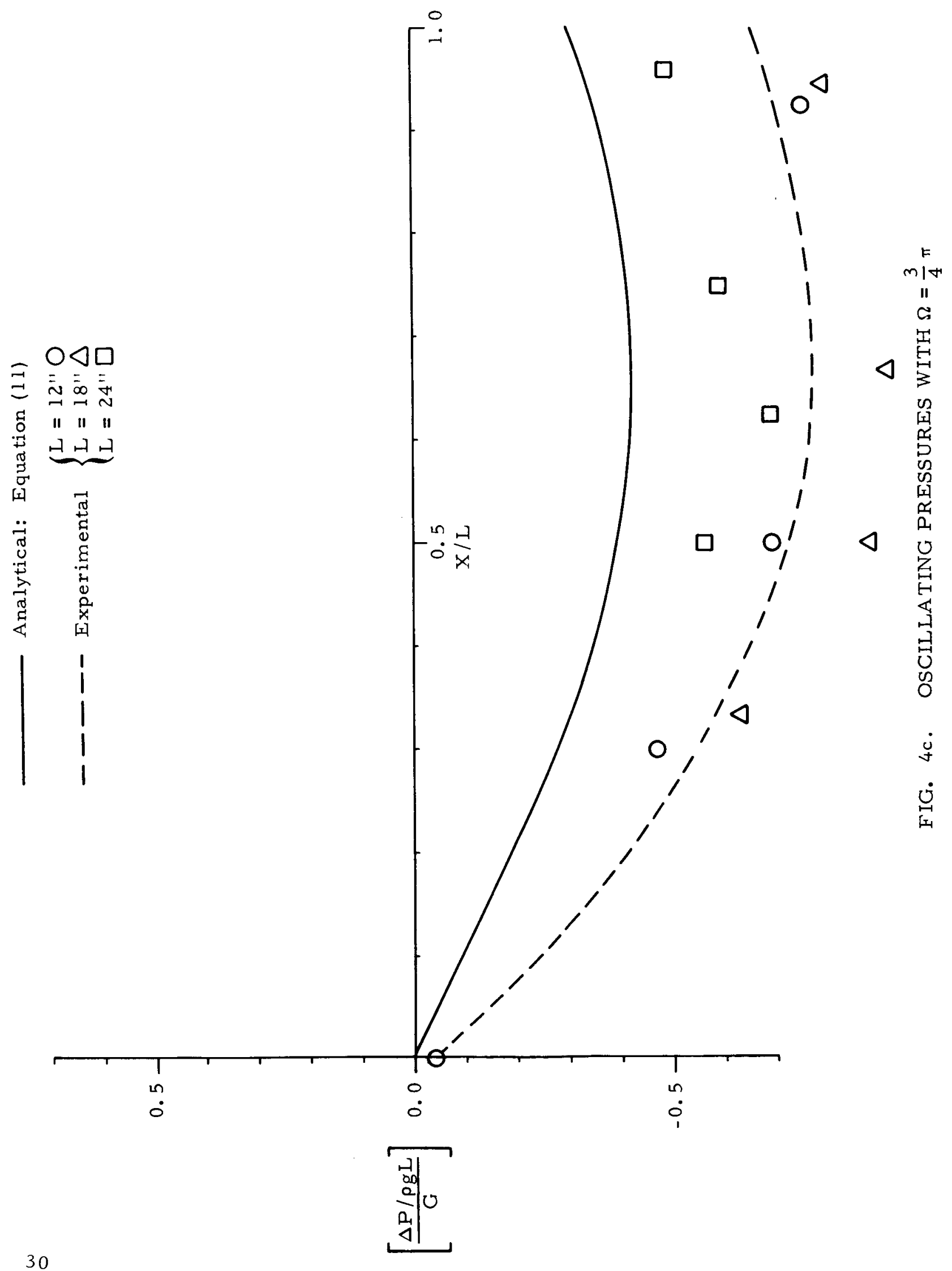




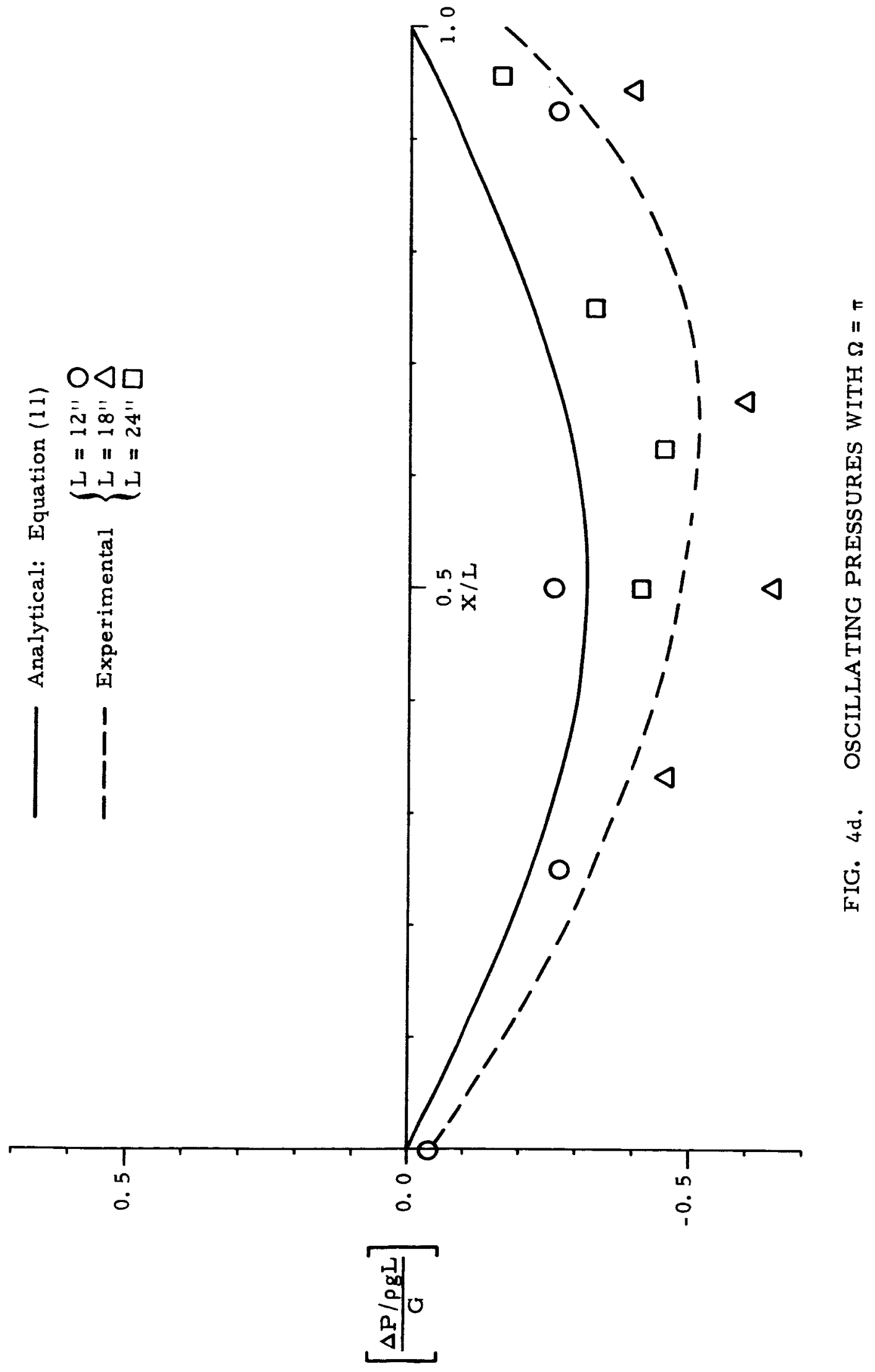




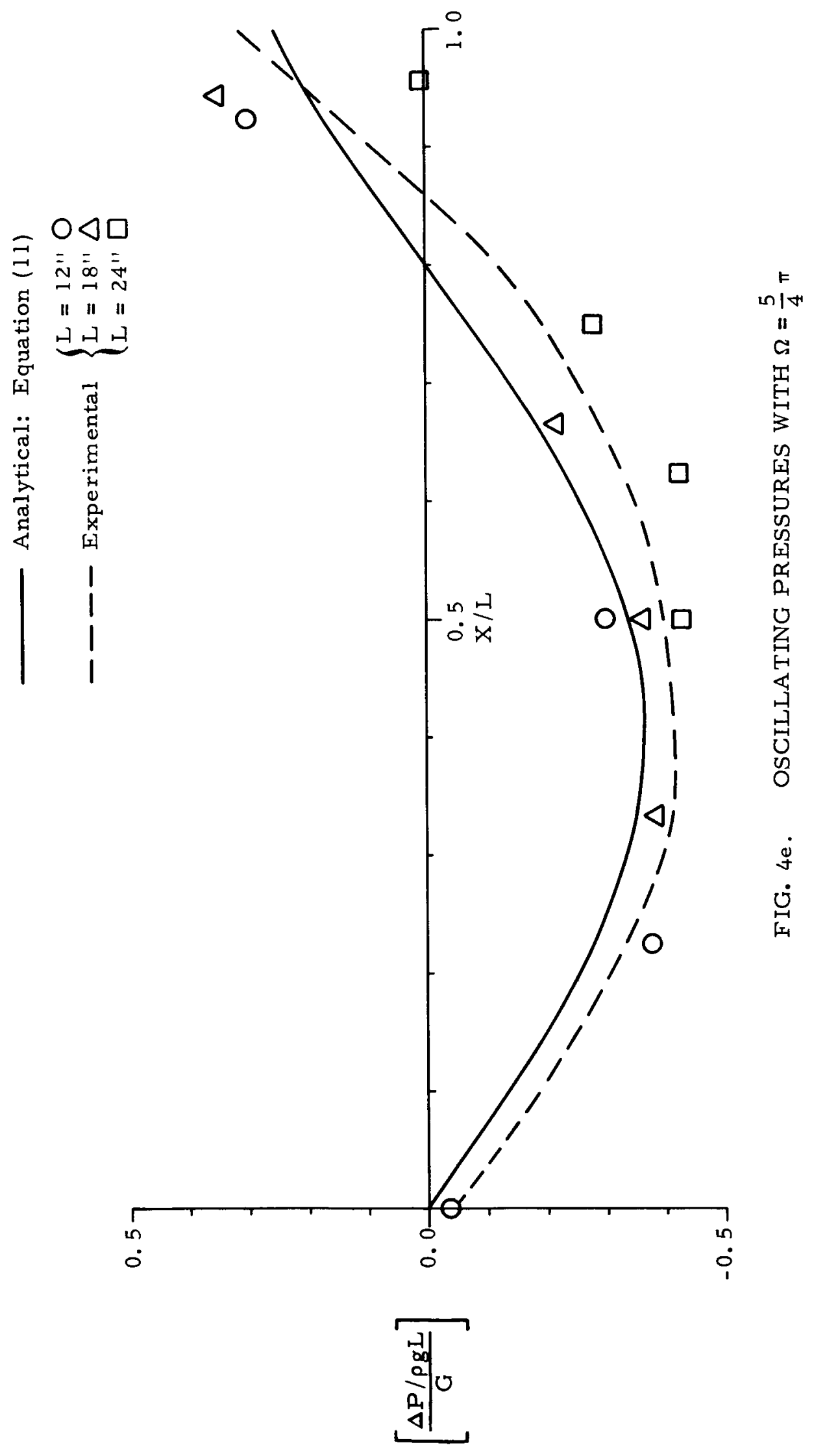




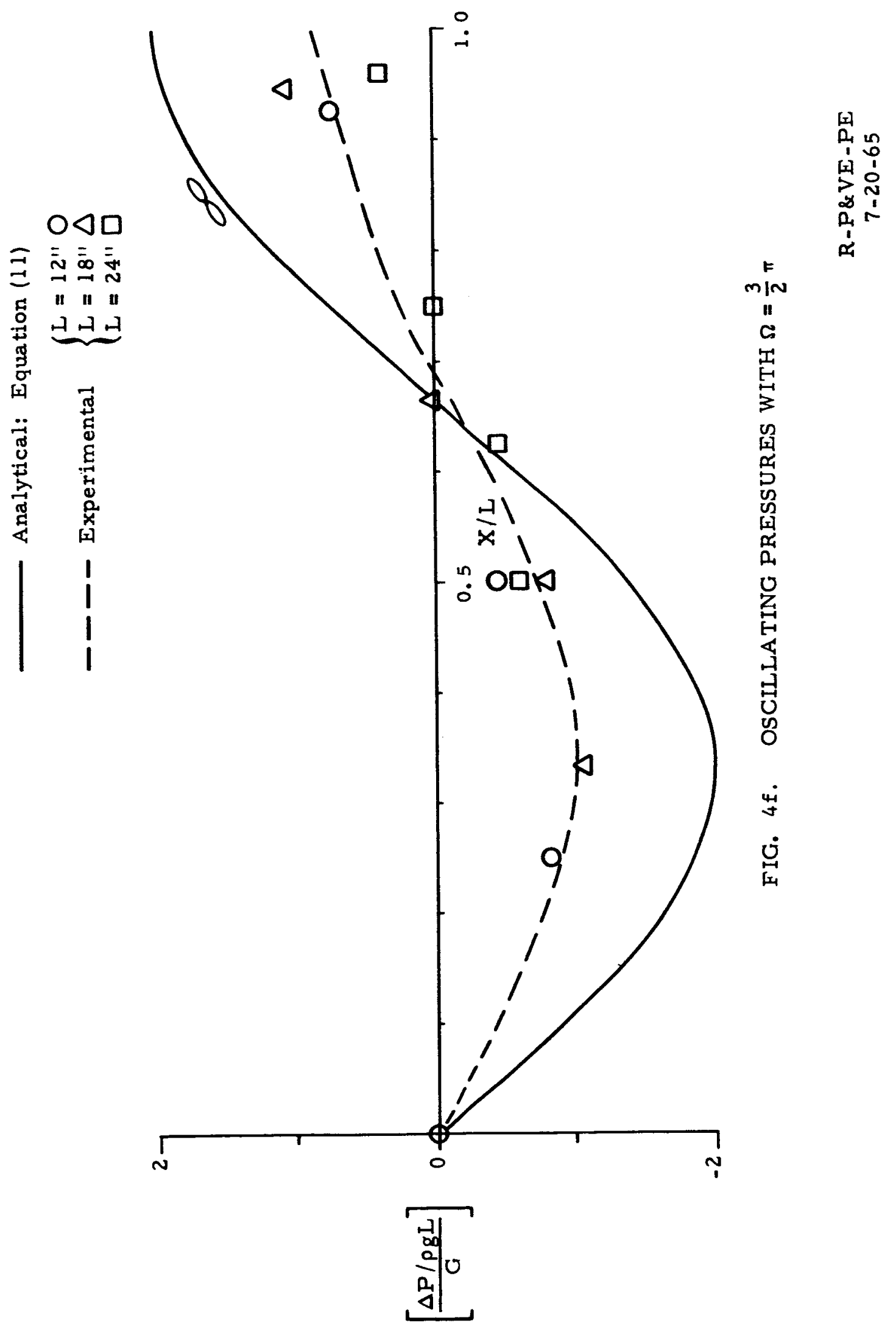




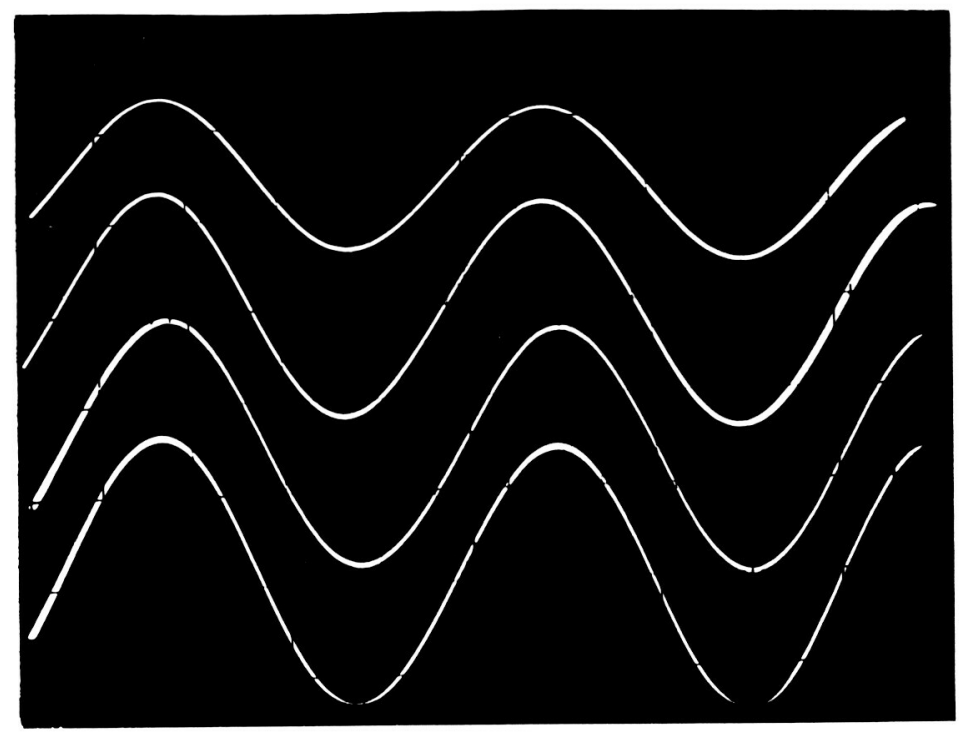

(a) $\Omega=\pi / 2$

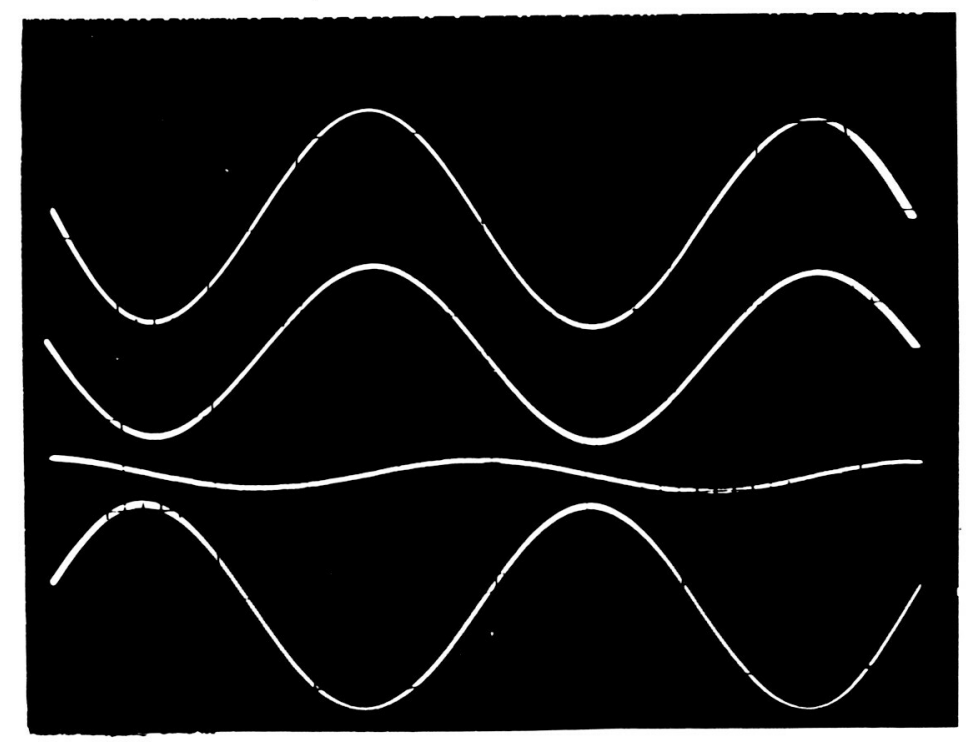

(b) $\Omega=3 \pi / 2$

FIGURE 5. OSCILLOSCOPE DISPLAY OF OSCILLATING PRESSURES. 


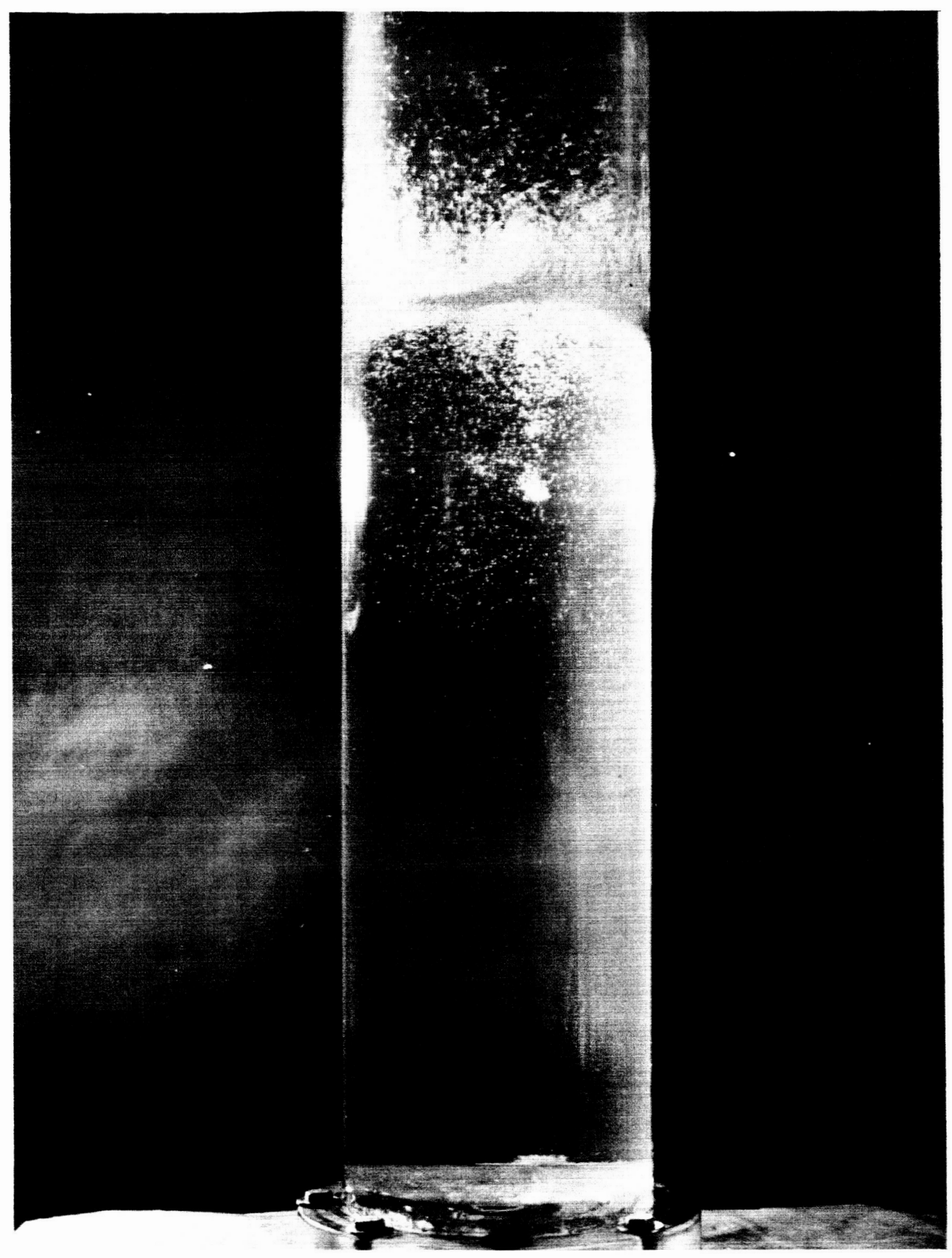

FIGURE 6a. INITIAL BUBBLE FORMATIONS IN A VIBRATED METHANOL COLUMN $(\Omega=\Pi / 4)$. 


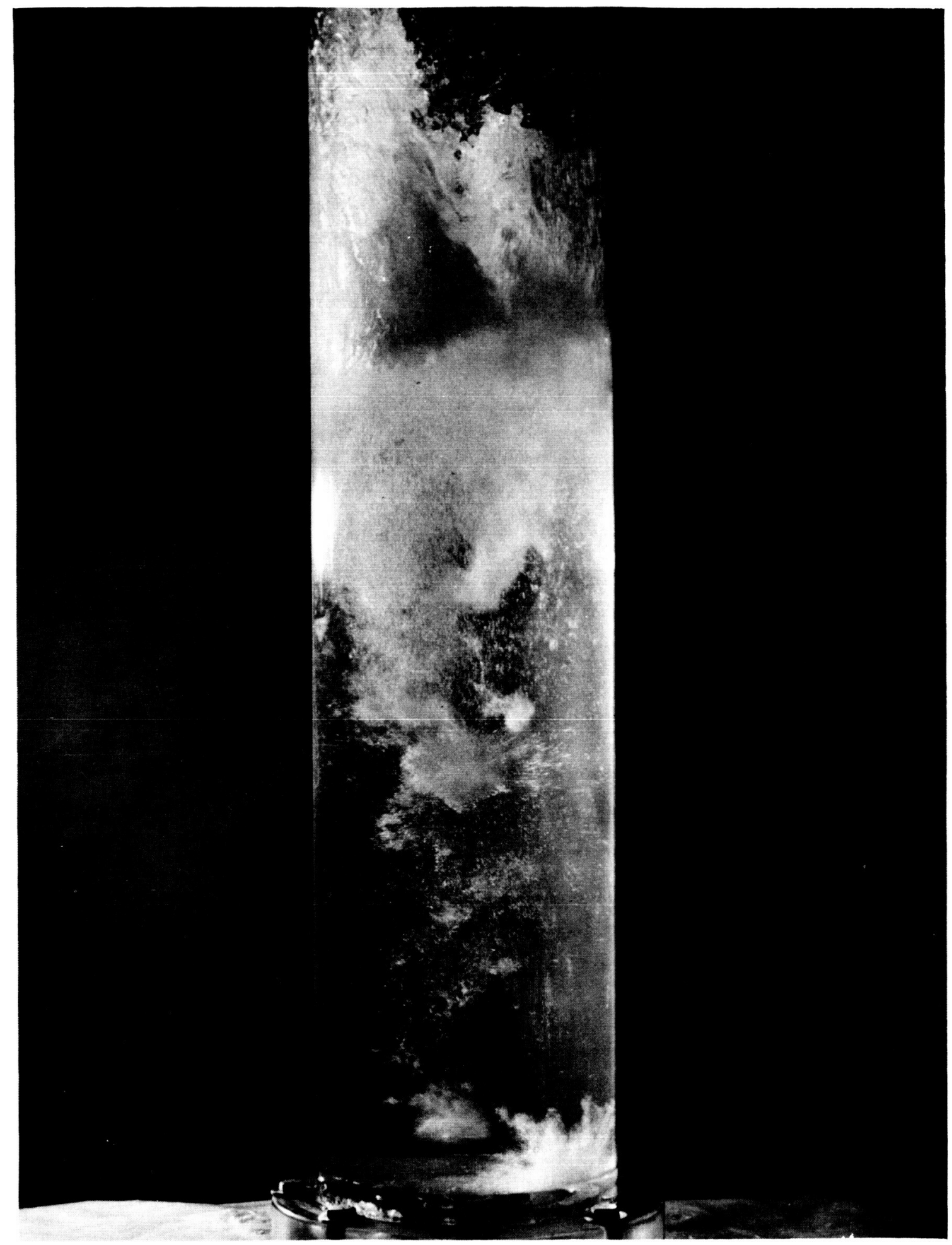

FIGURE 6b. GROW TH OF BUBBLE FORMATIONS IN A VIBRATED METHANOL COLUMN $(\Omega=\Pi / 4$. 


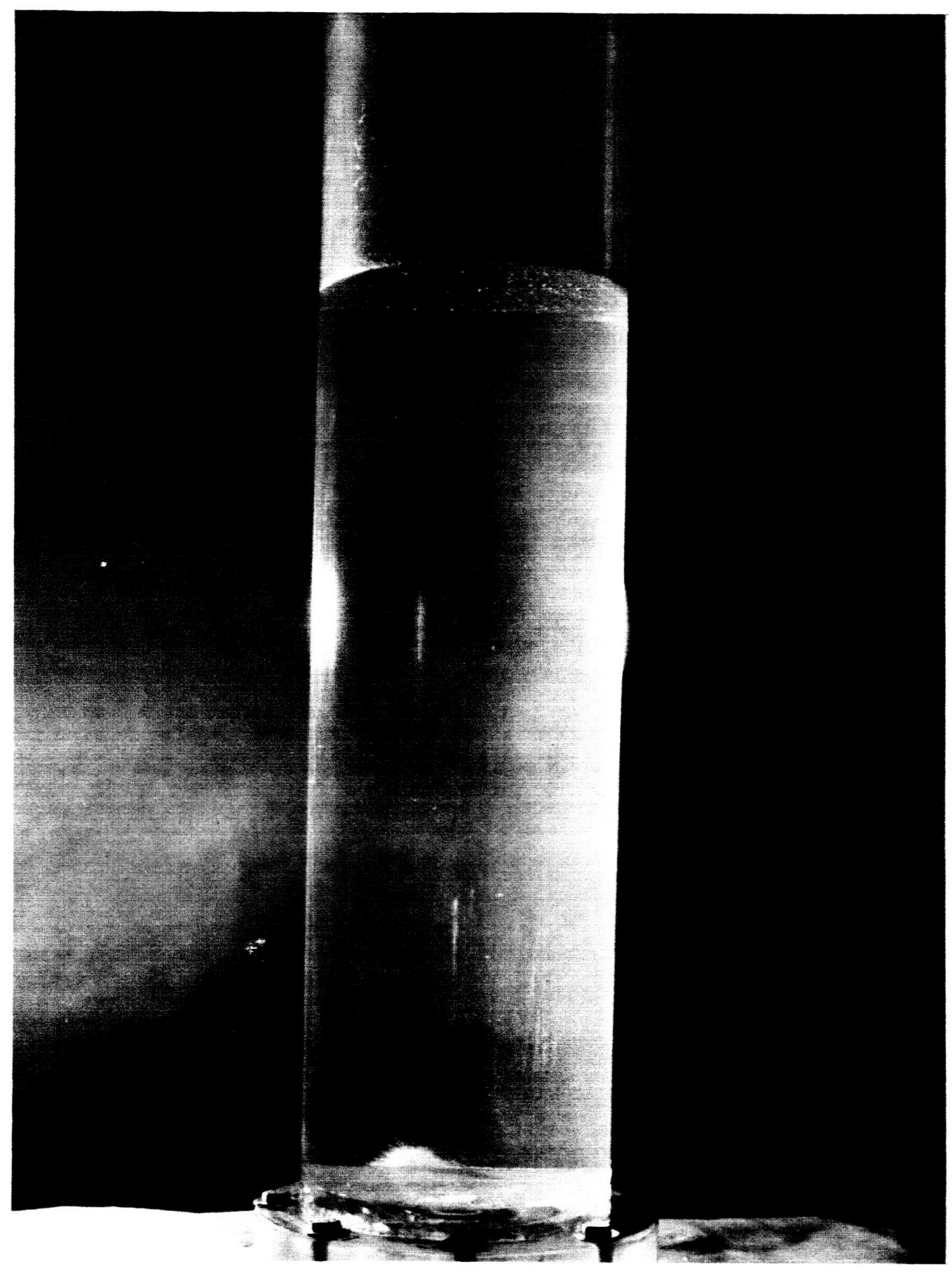

FIGURE 6c. INITIAL BUBBLE FORMATIONS IN A VIBRATED METHANOL COLUMN $\quad(\Omega=\Pi / 2$. 


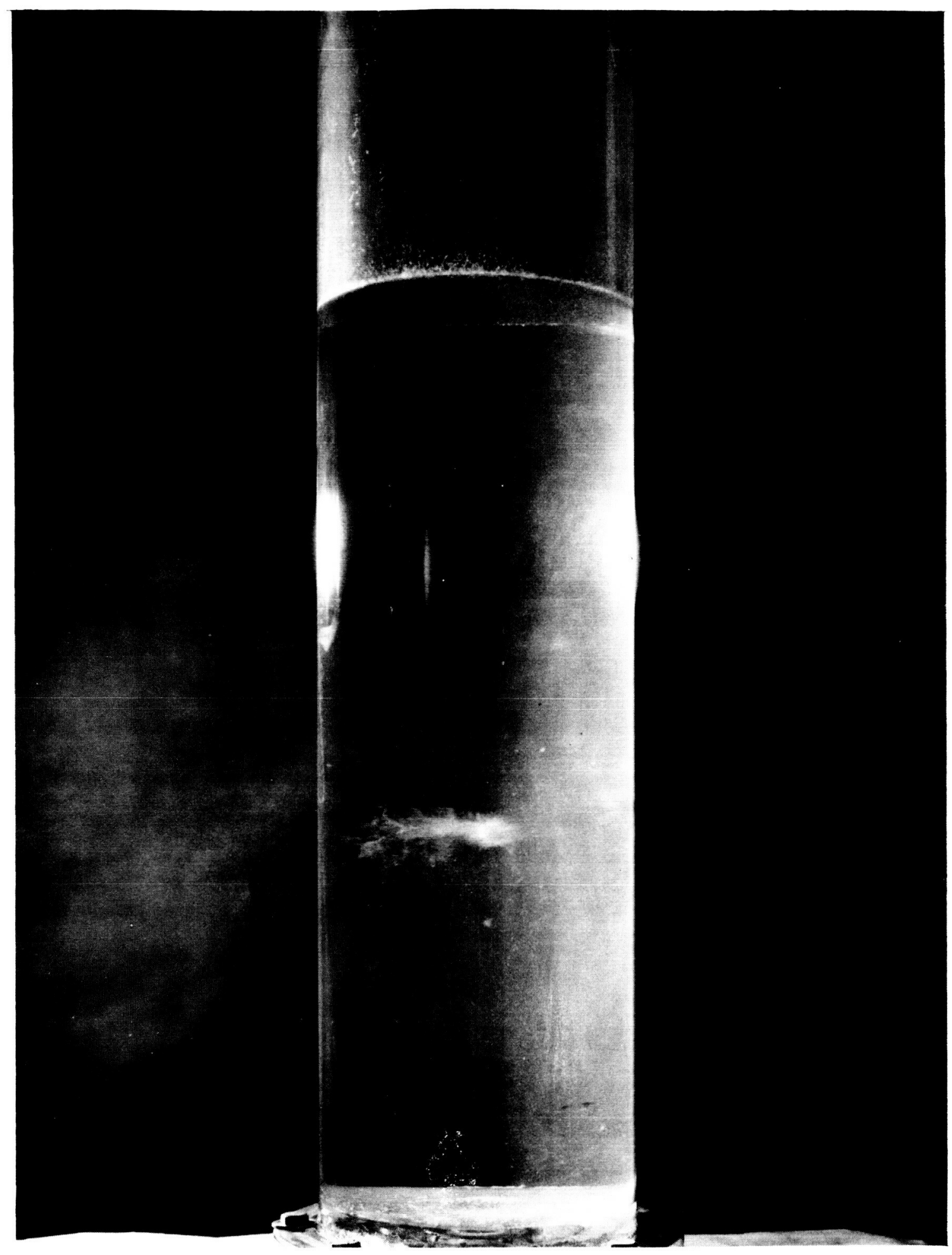

FIGURE 6d. INITIAL BUBBLE FORMATIONS IN A VIBRATED METHANOL COLUMN $(\Omega=\Pi)$. 


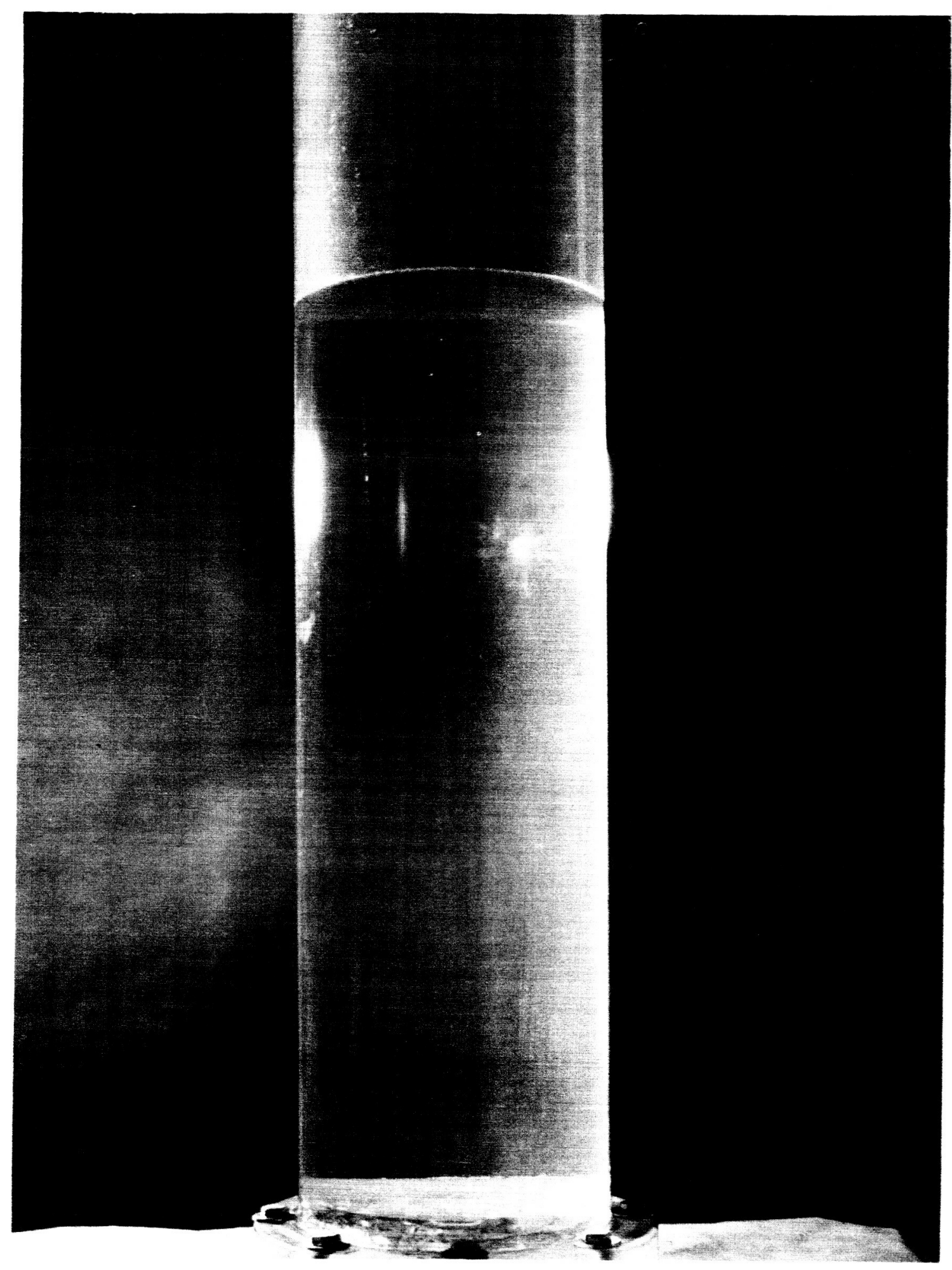

FIGURE 6e. INITIAL BUBBLE FORMATIONS IN A VIBRATED METHANOL COLUMN $(\Omega=3 \Pi / 2)$. 


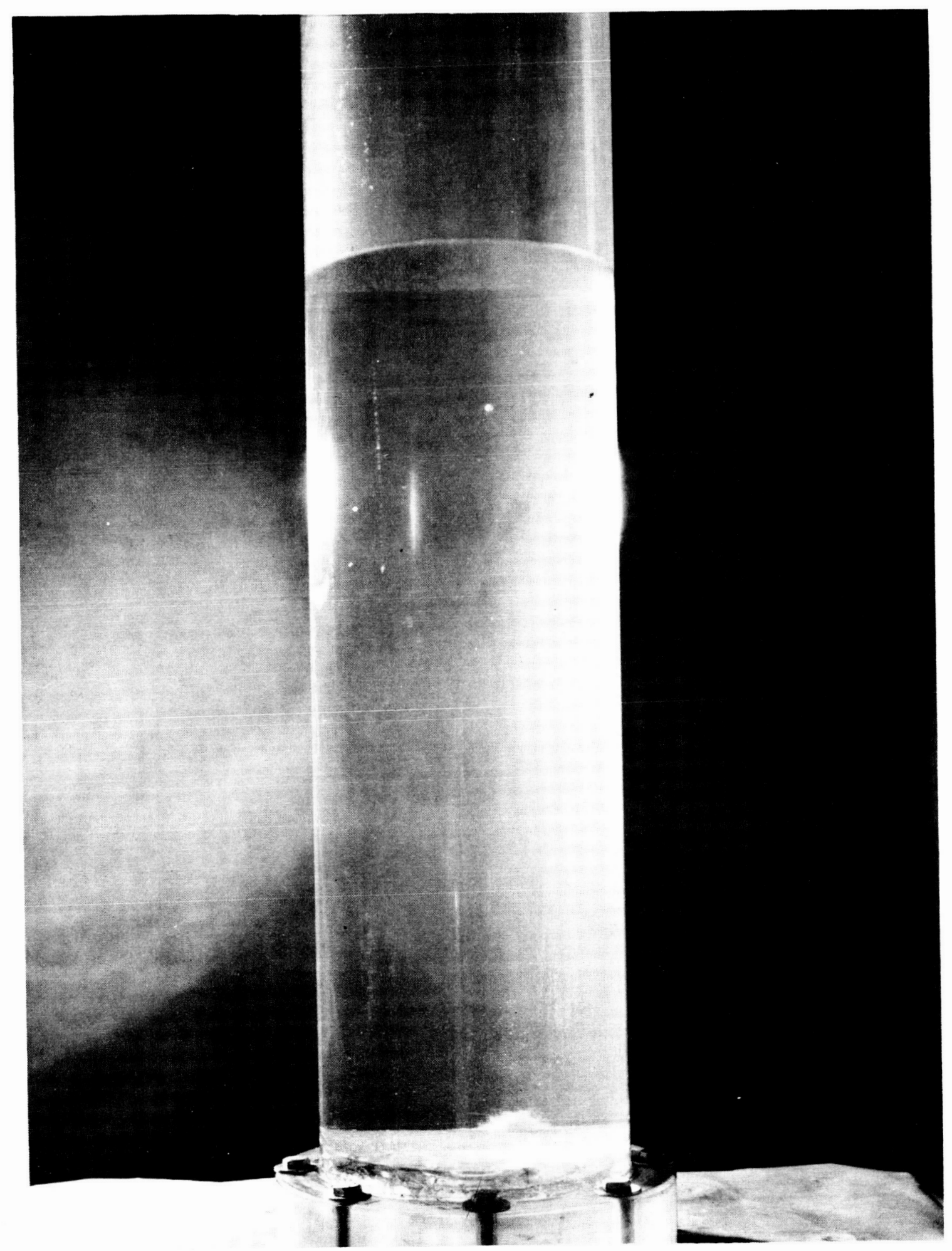

FIGURE 6f. INITIAL BUBBLE FORMATIONS IN A VIBRATED METHANOL COLUMN ( $\Omega=3 \Pi / 2)$ 


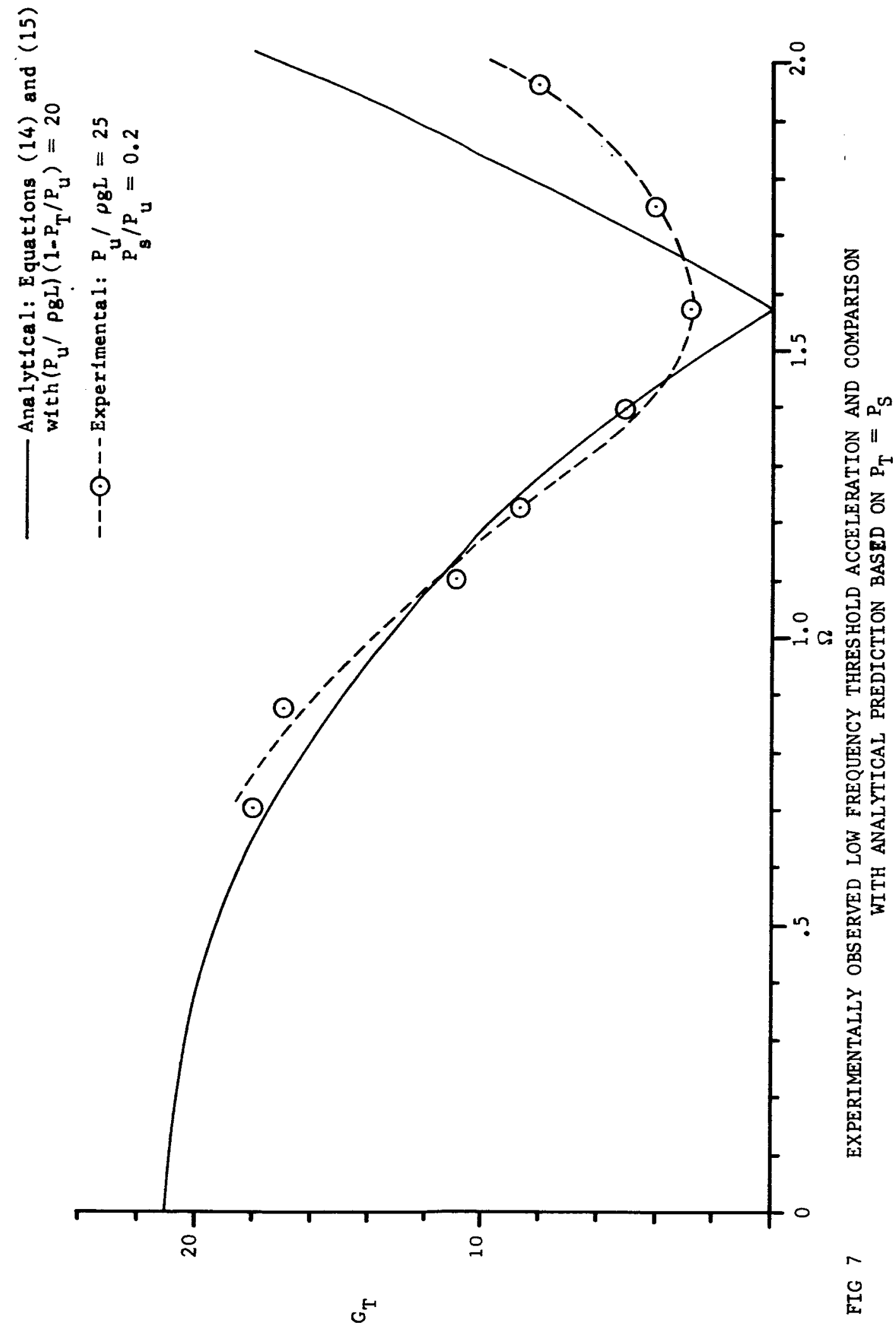




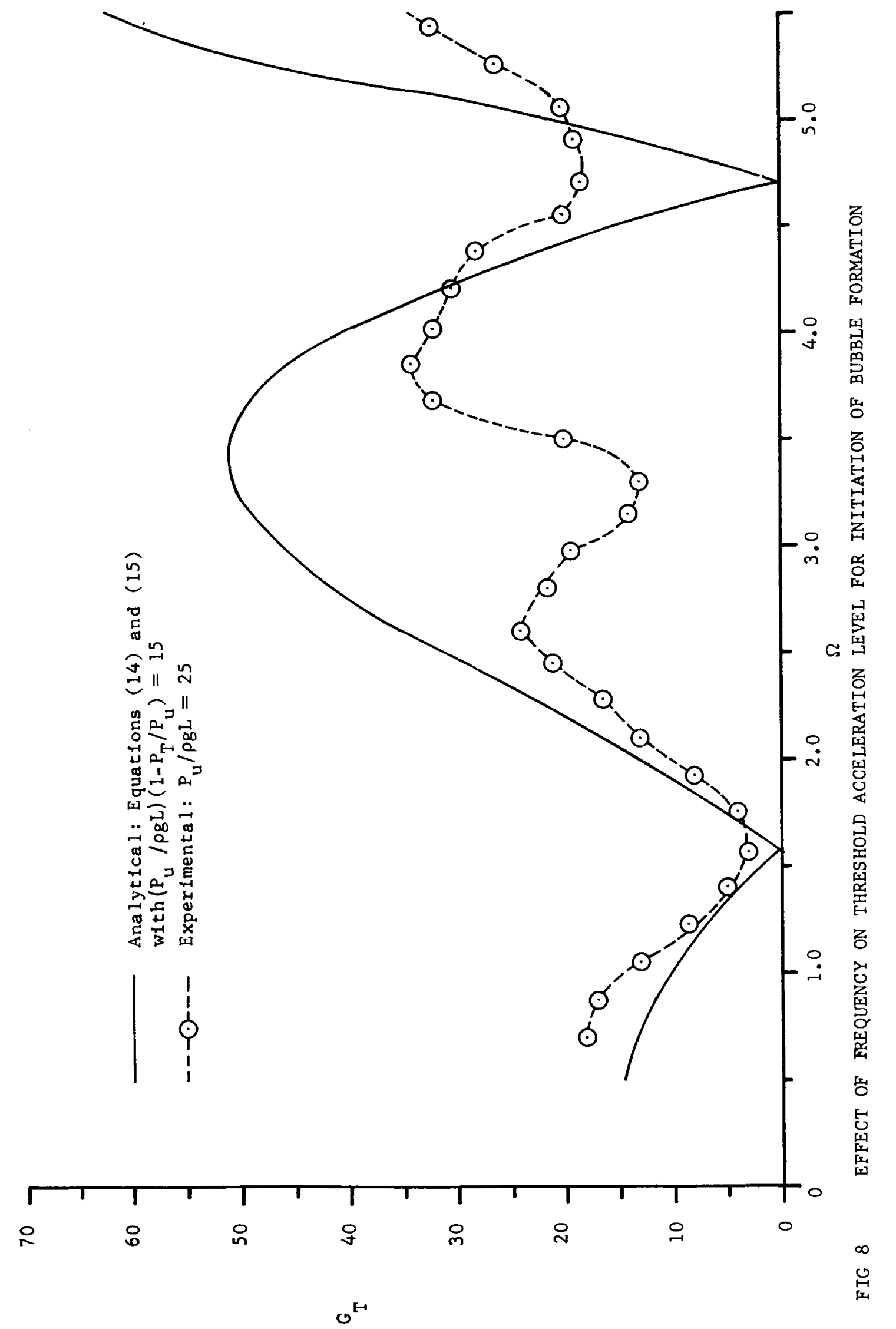




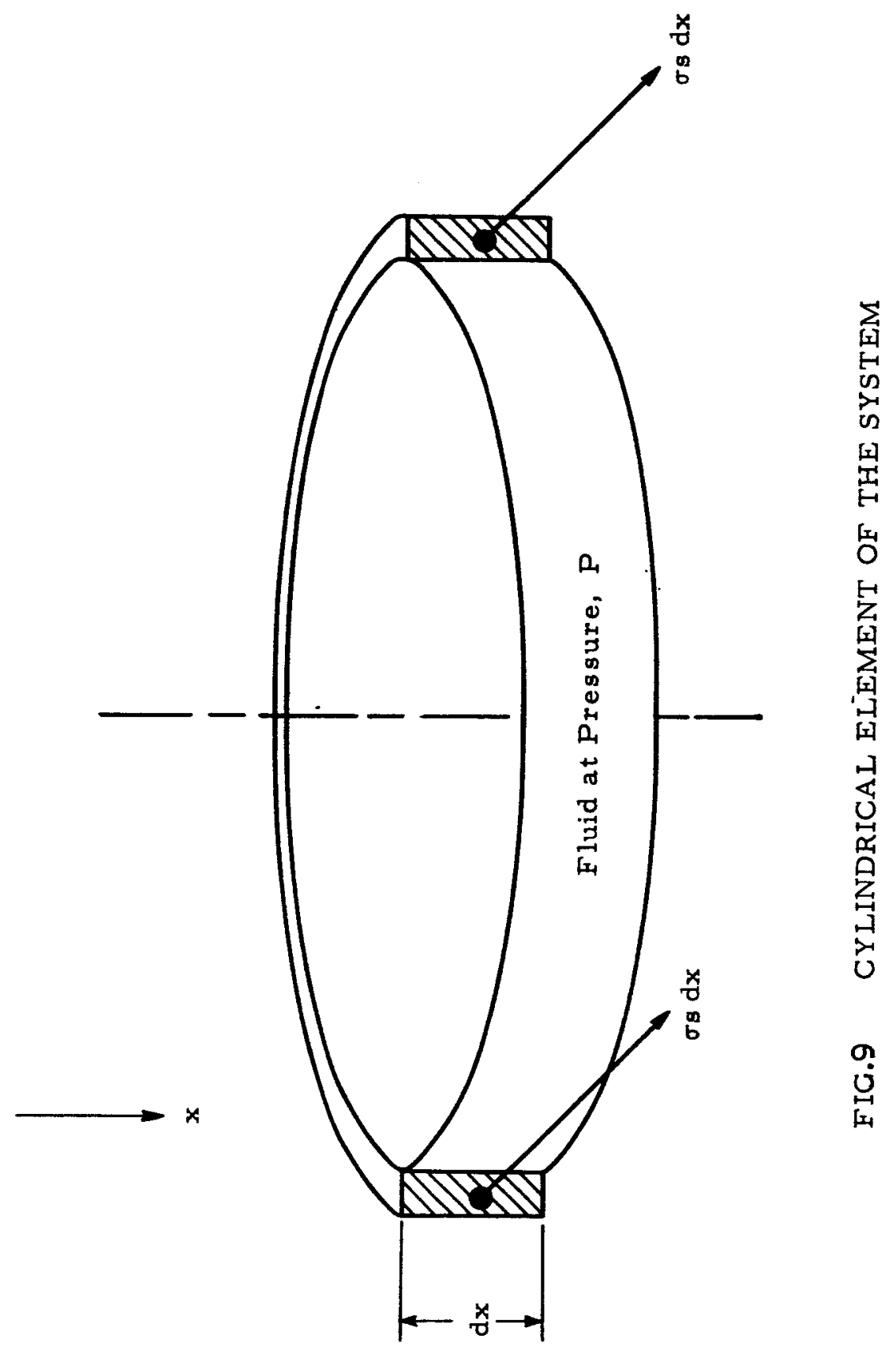




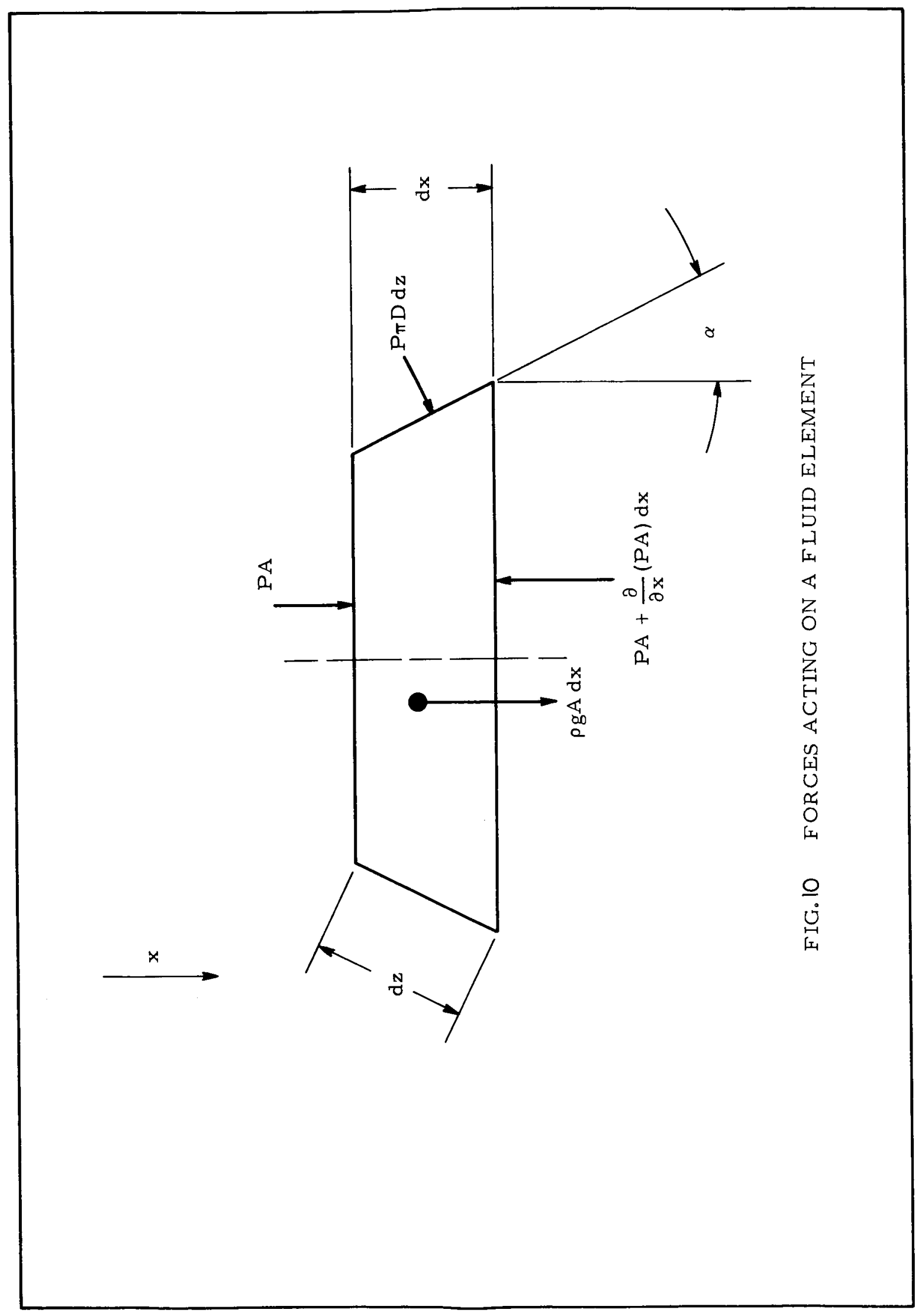




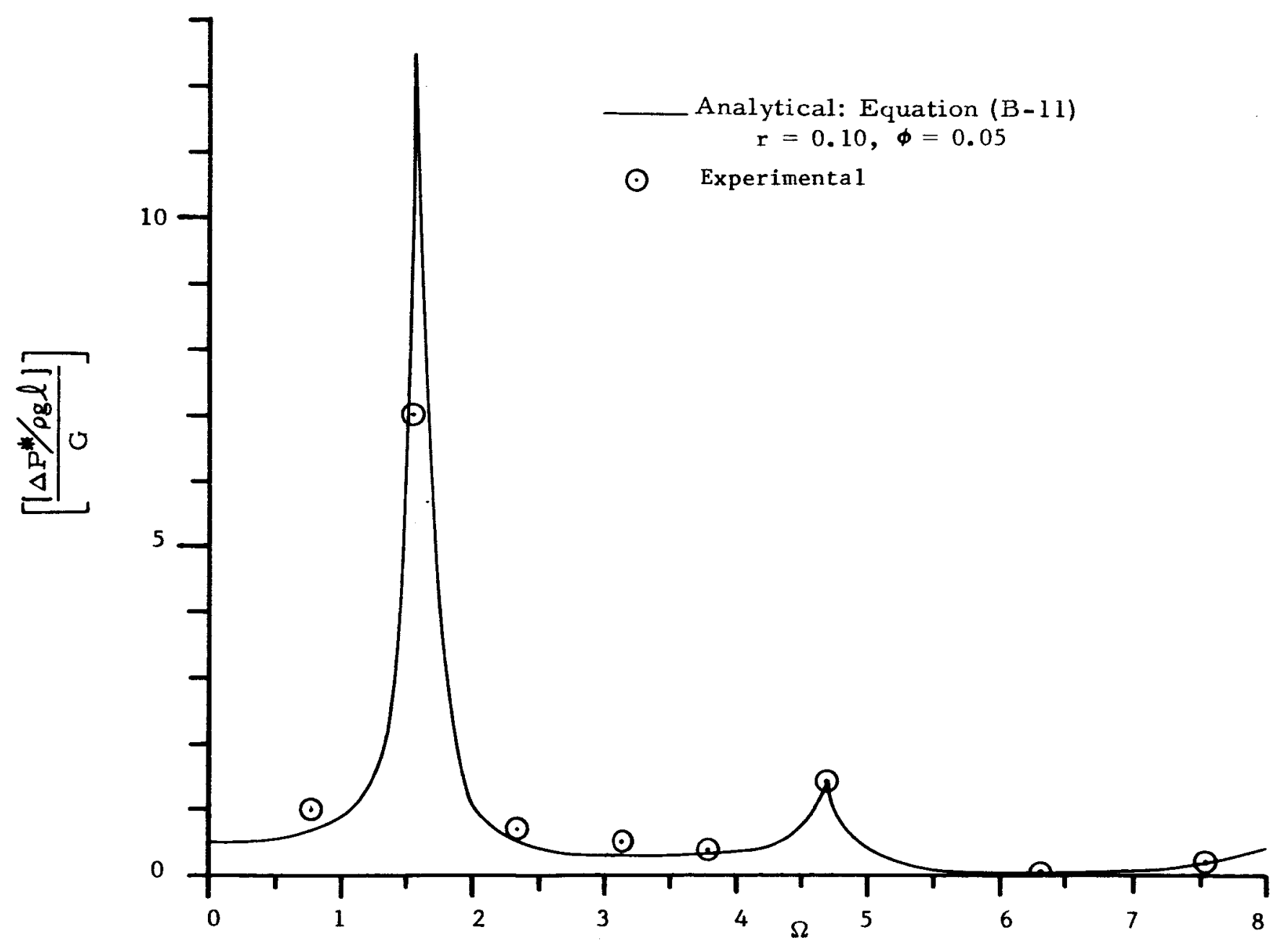

FIG 11 EFFECT OF FREQUENCY ON PRESSURE AMPLITUDE AT $x / L=0.5$ 


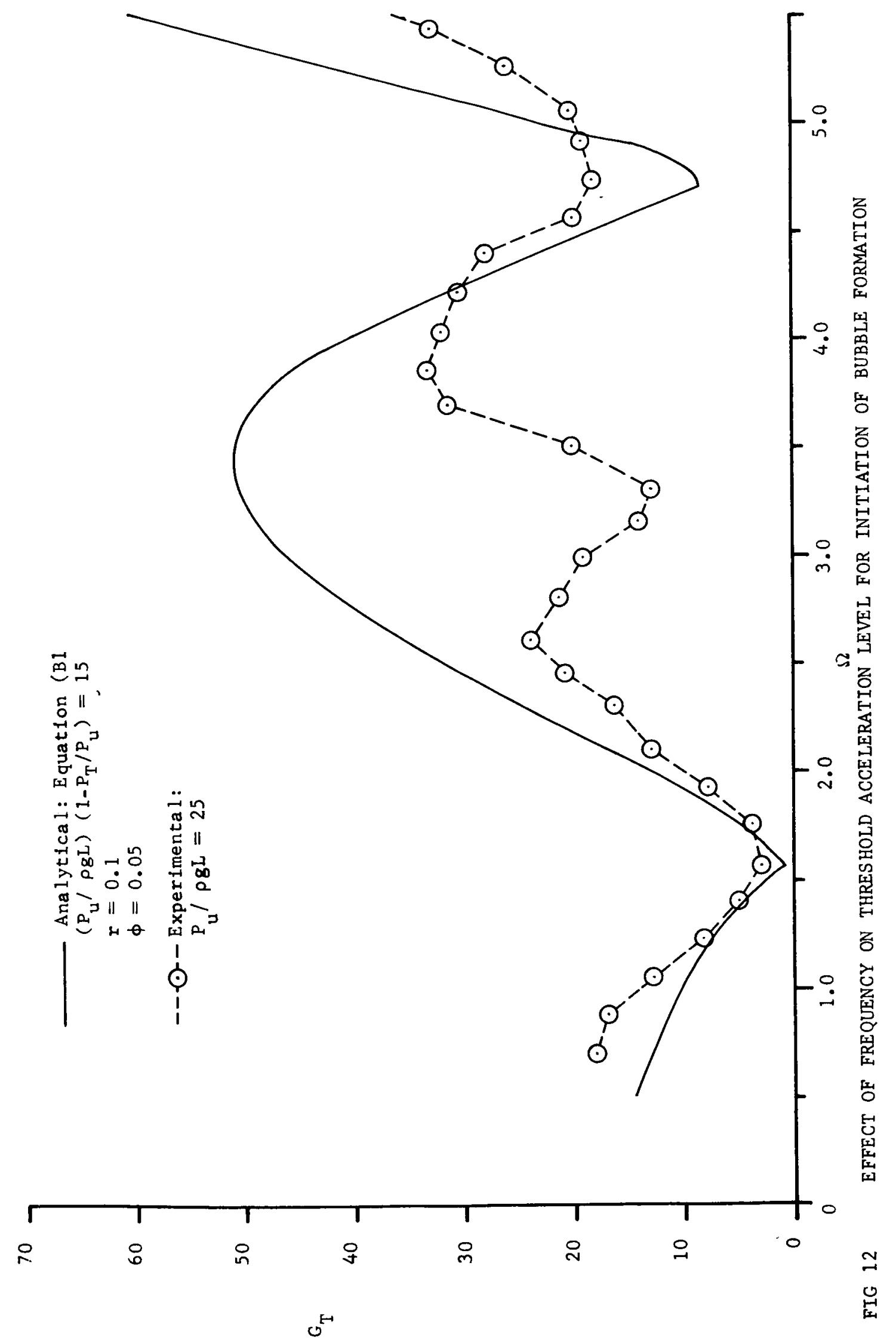




\section{REFERENCES (CONT.)}

12. Nielsen, L. E., Mechanical Properties of Polymers, Second Printing, Reinhold Publishing Corporation, 1963, pages 147, 150 , and 193.

13. Schlichting, H., Boundary Layer Theory, Fourth Edition, McGraw-Hill Book Company, Inc., 1960, page 75.

14. Streeter, V. L., Handbook of Fluid Dynamics, McGraw-Hill Book Company, Inc., 1961, pages $1-12$.

15. Ferry, J. D., Viscoelastic Properties of Polymers, John Wiley and Sons, Inc., 1961, page 310. 


\section{REFERENCES}

1. Ponder, C. A., D. H. Blount and C. G. Fritz, "Bubble Coalescence in a Longitudinally Vibrated Liquid Column, " NASA TMX-53180, George C. Marshall Space Flight Center, Huntsville, Alabama, December 16, 1964.

2. McAdams, W. H., Heat Transmission, Third Edition, McGrawHill Book Company, Inc., 1954, pages 402-404.

3. Bleich, H. H., "Longitudinal Forced Vibrations of Cylindrical Fuel Tanks," Jet Propulsion, Vol. 26, 1956, page 109.

4. Bleich, H. H., "Effect of Vibrations on the Motion of Small Gas Bubbles in a Liquid," Jet Propulsion, Vol. 26, page 958.

5. Baird, M. H. I., "Resonant Bubbles in a Vertically Vibrating Liquid Column, " Canadian Journal of Chemical Engineering, Vol. 41, 1963, page 52 .

6. Buchanan, R. H., G. Jameson and D. Oedjoe, "Cyclic Migration of Bubbles in a Vertically Vibrating Liquid Column, "Industrial and Engineering Chemistry Fundamentals, Vol. 1, No. 2, 1962, page 82 .

7. Hueter, T. F. and R. H. Bolt, Sonics, John Wiley and Sons, Inc. 1955, pages $38-41$ and 225-241.

8. Morse, P. M., Vibration and Sound, Second Edition, McGraw-Hill Book Company, Inc., 1958, pages 305-311.

9. Perry, J. H., C. H. Chilton and S. D. Kirkpatrick, Chemical Engineers' Handbook, Fourth Edition, McGraw-Hill Book Company, Inc., 1963, pages 3-54 and 3-89.

10. Lange, N. A. and G. M. Forker, Handbook of Chemistry, Tenth Edition, McGraw-Hill Book Company, Inc., 1961, page 1673.

11. Modern Plastics Encyclopedia, Vo1. 39, No. 1A, Breskin Publications, Inc., 1961, Plastics Properties Chart. 


\section{PRESSURE DISTRIBUTION AND BUBBLE FORMATION INDUCED BY LONGITUDINAL VIBRATION OF \\ A FLEXIBLE LIQUID-FILLED CYLINDER}

By R. J. Schoenhals and T. J. Overcamp

The information in this report has been reviewed for security classification. Review of any information concerning Department of Defense or Atomic Energy Commission programs has been made by the MSFC Security Classification Officer. This report, in its entirety, has been determined to be unclassified.

This document has also been reviewed and approved for technical accuracy.

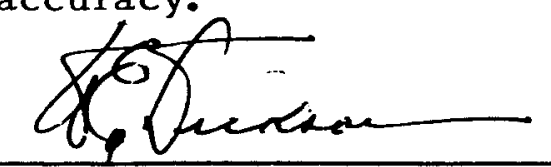

W. E. DICKSON

Chief, Propulsion Cryogenics Section

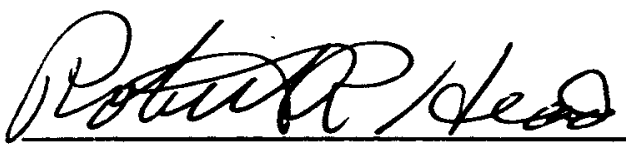

R. R. HEAD

Chief, Applied Mechanical Research Branch

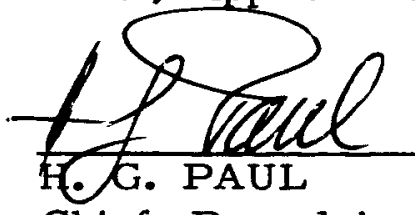

Chief, Propulsion Division

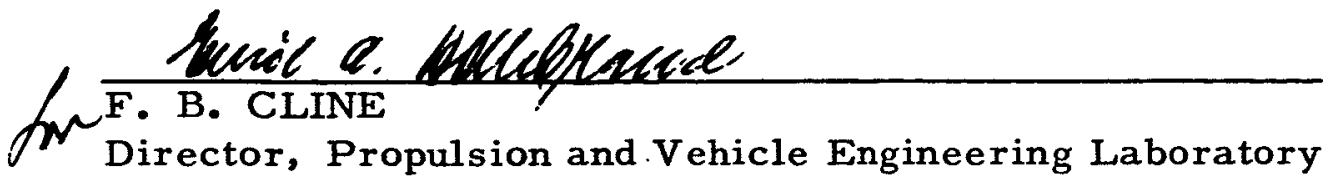




\section{DISTRIBUTION}

R-DIR

$\mathrm{R}-\mathrm{AST} \mathrm{RO}-\mathrm{N}$

$R-P \& V E-D I R$

$R-P \& V E-M$

$\mathrm{R}-\mathrm{P} \& \mathrm{VE}-\mathrm{P}$

$R-P \& V E-P$

$R-P \& V E-P A$

$R-P \& V E-P E$

$R-P \& V E-P M$

$R-P \& V E-P P$

$R-P \& V E-P R$

$R-P \& V E-P T$

$R-P \& V E-R T$

$R-P \& V E-S$

$R-P \& V E-V$

$R-R P-D I R$

R-TEST-DIR

R-TEST-SP

R-TEST - T

M-MS-I

$\mathrm{M}-\mathrm{MS}-\mathrm{H}$
Mr. Weidner

Mr. Moore

Mr. Cline

Dr. Lucas

Mr. Paul

Mr. McCool

Mr. Thomson

Dr. Head

Mr. Fuhrmann

Mr. Heusinger

Mr. Eby

Mr. Wood

$\mathrm{Mr}$. Hofues

Mr. Kroll

Mr. Aberg

Dr. Stuhlinger

Mr. Heimburg

Mr. Pearson

Mr. Driscoll

Mr. Remer

Mr. Akens

Defense Documentation Center $\quad$ (20 copies)

Cameron Station

Alexandria, Virginia 22314

Scientific and Technical Information Facility (25 copies)

Attn: NASA Representative (S-AK/RKT)

P.O. Box 33

College Park, Maryland 20740

Head, Department of Mechanical Engineering

School of Engineering

Michigan State University

East Lansing, Michigan

Dr. R. J. Schoenhals (10 copies)

Department of Mechanical Engineering

School of Engineering

Purdue University

Lafayette, Indiana 


\section{DISTRIBUTION (Cont'd)}

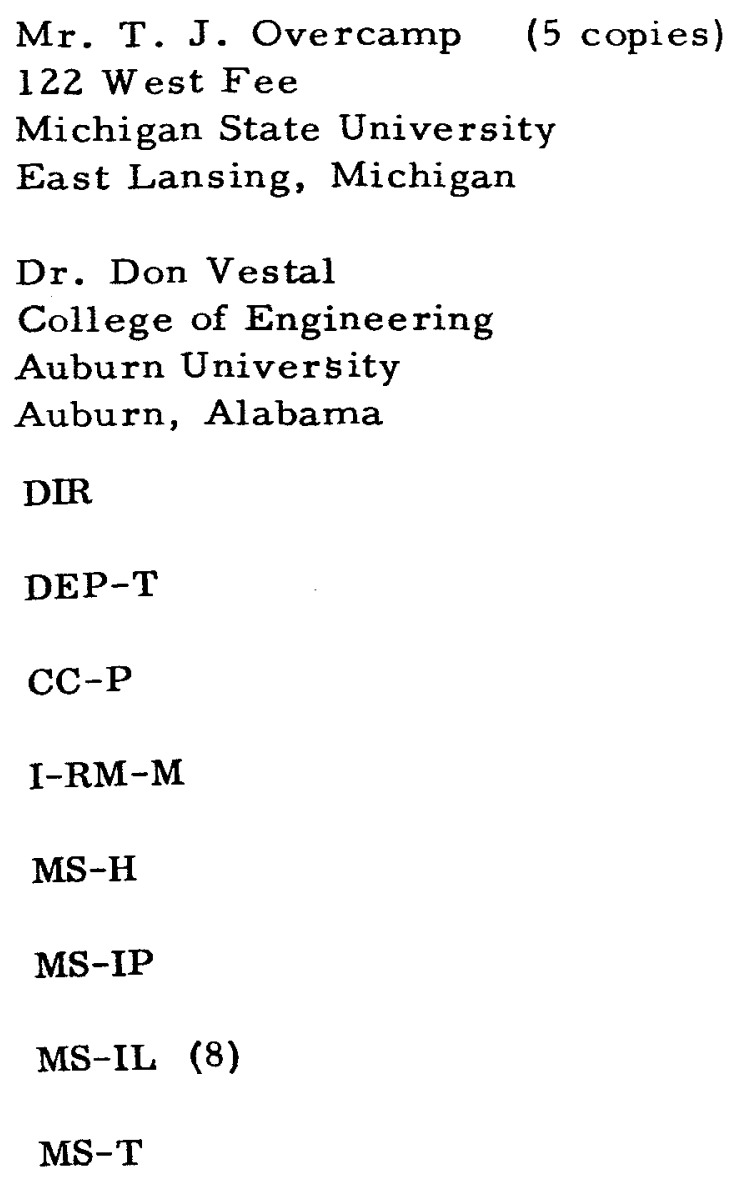

